\title{
PRAK Interacts with DJ-1 and Prevents Oxidative Stress-Induced Cell Death
}

\author{
Jing Tang, ${ }^{1,2}$ Jinghua Liu, ${ }^{1}$ Xue Li, ${ }^{1}$ Yuyun Zhong, ${ }^{1}$ Tianyu Zhong, ${ }^{1}$ Yawei Liu, \\ Jiang Huai Wang, ${ }^{3}$ and Yong Jiang ${ }^{1}$ \\ ${ }^{1}$ State Key Laboratory of Organ Failure Research, Key Laboratory of Transcriptomics and Proteomics, Ministry of Education of China, \\ Key Laboratory of Proteomics of Guangdong Province, Southern Medical University, Guangzhou 510515, China \\ ${ }^{2}$ Nanfang Hospital, Southern Medical University, Guangzhou 510515, China \\ ${ }^{3}$ Department of Surgery, Cork University Hospital, University College Cork, Cork, Ireland
}

Correspondence should be addressed to Yong Jiang; jiang48231@163.com

Received 23 May 2014; Accepted 27 August 2014; Published 14 October 2014

Academic Editor: Ozcan Erel

Copyright (C) 2014 Jing Tang et al. This is an open access article distributed under the Creative Commons Attribution License, which permits unrestricted use, distribution, and reproduction in any medium, provided the original work is properly cited.

\begin{abstract}
As a core member of p38 MAPK signal transduction pathway, p38 regulated/activated kinase (PRAK) is activated by cellular stresses. However, the function of PRAK and its downstream interacting partner remain undefined. Using a yeast two-hybrid system, we identified DJ-1 as a potential PRAK interacting protein. We further verified that DJ-1 bound to PRAK in vitro and in vivo and colocalized with PRAK in the nuclei of NIH3T3 cells. Furthermore, following $\mathrm{H}_{2} \mathrm{O}_{2}$ stimulation the majority of endogenous DJ-1 in $\mathrm{PRAK}^{+/+}$cells still remained in the nucleus, whereas most DJ-1 in PRAK ${ }^{-/-}$cells translocated from the nucleus into the cytoplasm, indicating that PRAK is essential for DJ-1 to localize in the nucleus. In addition, PRAK-associated phosphorylation of DJ-1 was observed in vitro and in vivo of $\mathrm{H}_{2} \mathrm{O}_{2}$-challenged PRAK ${ }^{+/+}$cells. Cytoplasmic translocation of DJ- 1 in $\mathrm{H}_{2} \mathrm{O}_{2}$-treated PRAK ${ }^{-/-}$cells lost its ability to sequester Daxx, a death protein, in the nucleus, and as a result, Daxx gained access to the cytoplasm and triggered cell death. These data highlight that DJ-1 is the downstream interacting target for PRAK, and in response to oxidative stress PRAK may exert a cytoprotective effect by facilitating DJ-1 to sequester Daxx in the nucleus, thus preventing cell death.
\end{abstract}

\section{Introduction}

p38 mitogen-activated protein kinase (MAPK), a stressactivated Ser/Thr protein kinase, belongs to the MAP kinase superfamily. Study shows that p38 MAPKs are involved in cell growth [1], cell apoptosis [2], and cell cycle [3]. By regulating inflammatory processes [4], stress responses [5], transcriptional activity [6], and cytoskeletal reorganization [7], p38 MAPK plays important roles in pathological conditions including cardiomyocyte hypertrophy [8], ischemia/ reperfusion injury [9], neuronal pathology [10], infectious diseases [11], wound healing, and tissue remodeling [12].

p38 regulated/activated kinase (PRAK) or MAPK activated protein kinase 5 (MK5), ubiquitously expressed in almost all human tissues, is a 471 amino acid protein with 20-30\% sequence homology to the known MAPK-regulated protein kinases RSK1/2/3, MNK1/2, and MK2/3 [13]. PRAK was originally identified as a p38 MAKP-activated protein [13], but afterward work found that it was also activated by extracellular signal-regulated kinase 3/4 (ERK3/4), indicating involvement of PRAK in both p38- and ERK3/4-mediated signal transduction pathways. The evidence has suggested that PRAK/MK5 may regulate actin polymerization and cell motility and function as a tumor suppressor [14-22]. Recently, PRAK has been showed to phosphorylate several substrates including FoxO1, FoxO3, and Rheb, indicating that the biological role of PRAK is far from completely understood [23-25].

Endogenous PRAK is primarily located in the cytoplasm, whereas exogenous PRAK predominates in the nucleus [26]. A sequence analysis of PRAK revealed that PRAK contains a putative nuclear localization sequence (NLS) and a nuclear 
export sequence (NES), and both of them are required for the shuttling of PRAK between nucleus and cytoplasm. Following stimulation with arsenite, the nuclear PRAK was markedly reduced due to a decrease in the nuclear import of PRAK and an increase in the nuclear export of PRAK [26]. Furthermore, the nuclear import of PRAK was independent of p38 activation, whereas the nuclear export required p38mediated phosphorylation of PRAK. However, the function of PRAK shuttling between nucleus and cytoplasm in response to different cellular stresses remains unclear.

Here, we report that DJ-1, originally found as a mitogendependent oncogene product [27], is a downstream interacting protein for PRAK. DJ-1 bound to PRAK both in vitro and in vivo and colocalized with PRAK in the nuclei of NIH3T3 cells. Functional studies revealed that PRAK can activate DJ-1 and help DJ-1 to localize in the nucleus. Phosphorylation of DJ-1 following $\mathrm{H}_{2} \mathrm{O}_{2}$ treatment was observed in $\mathrm{PRAK}^{+/+}$cells but not in $\mathrm{PRAK}^{-/-}$cells. Consistently, endogenous DJ-1 in $\mathrm{PRAK}^{+/+}$cells was mainly located in the nucleus even after the cells were challenged with $\mathrm{H}_{2} \mathrm{O}_{2}$, whereas most DJ-1 in PRAK ${ }^{-/-}$cells translocated from the nucleus into the cytoplasm in response to oxidative stress. As a result, DJ-1 was unable to sequester its interacting partner, a death protein Daxx in the nuclei of PRAK ${ }^{-/-}$cells, thereby causing an increased cell death.

\section{Materials and Methods}

2.1. Plasmids and Reagents. A full-length human DJ-1 cDNA was amplified by PCR from a human adult brain cDNA library (Invitrogen) using primers $5^{\prime}$-GTGGATCCGCTTCCAAAAGAGCTCTGGTCATC- $3^{\prime}$ and $5^{\prime}$-TGGAATTCCTAGTCTTTAAGAACAAGTGGAGC-3' (containing restriction enzyme cleavage sites $B a m \mathrm{HI}$ and EcoRI) and cloned into pGEX-KG (Pharmacia) and pcDNA3-Flag (Clontech) to produce GST-tagged and Flag-tagged DJ-1. In addition, this DJ-1 cDNA was cloned into pEGFP-C2 (Clontech) and pGADT7 (Clontech) to produce GFP-tagged and ADtagged DJ-1 using primers 5' -GTGAATTCATGGCTTCCAAAAGAGCTCTGGTCATC- $3^{\prime}$ and $5^{\prime}$-TGGGATCCCGGTCTTTAAGAACAAGTGGAGC- $3^{\prime}$ (containing restriction enzyme cleavage sites EcoRI and BamHI). DJ-1 cDNA was cloned into pECFP-C1 (Clontech) to produce CFP-tagged DJ-1 using primers $5^{\prime}$-GTGAATTCTATGGCTTCCAAAAGAGCTCTGGTCATC- $3^{\prime}$ and $5^{\prime}$-TGGGATCCCGGTCTTTAAGAACAAGTGGAGC-3' (containing restriction enzyme cleavage sites EcoRI and BamHI). A full-length human PRAK cDNA was obtained from pcDNA3-HA-PRAK (kindly provided by Dr. Jiahuai Han, The Scripps Research Institute, La Jolla) by NdeI and BamHI dual-enzyme digestion and subcloned into pGBKT7 and pET-14b to produce DBDPRAK and His-tagged PRAK fusion protein. This PRAK cDNA was also cloned into pEYFP-C1 (Clontech) to produce YFP-tagged PRAK fusion protein using primers $5^{\prime}$ TAGAATTCATCGGAGGAGAGCGACATGGACA- $3^{\prime}$ and $5^{\prime}$-TAGGATCCTTATTGGGATTCGTGGGACGT-3' (containing restriction enzyme cleavage sites EcoRI and Bam $\mathrm{HI}$ ). All DNA plasmids were isolated and purified with Qiagen
Endo-free Plasmid Maxi Kit. All other chemicals, unless indicated, were from Sigma-Aldrich.

2.2. Yeast Two-Hybrid Screening. The Matchmaker GAL4 Two-hybrid System 3 (Clontech, protocol PT3247-1) was used to screen for proteins that interact with PRAK. pGBKT7PRAK was transformed into the yeast strain AH109 as the bait, and a human heart cDNA library previously transformed into the yeast strain Y187 (Clontech) was used as the prey. Approximately $1 \times 10^{6}$ transformants were screened. After being mated, the mixtures of the bait and the prey were plated onto SD/-Ade/-His/-Leu/-Trp/X- $\alpha$-gal plates and allowed to grow at $30^{\circ} \mathrm{C}$ for $4-6$ days. The yeast colonies were assayed for $\beta$-galactosidase activity using a colony-lift filter and positive clones were subjected to sequencing.

2.3. Yeast Two-Hybrid Interaction Assay. Plasmids pGBKT7PRAK and pGADT7-DJ-1 were transformed into the yeast strains Y187 and AH109, respectively. Yeast clones of AH109 expressing AD-DJ-1 and Y187 expressing DBD-PRAK were mixed and mated at $30^{\circ} \mathrm{C}$ for $24 \mathrm{hrs}$. To select the diploid, mated mixtures were spread on SD/-Leu/-Trp plates and the yeast colonies were then transferred onto SD/-Ade/-His/ -Leu/-Trp/X- $\alpha$-gal plates for assessing $\beta$-galactosidase activity. Positive and negative controls were performed in parallel.

2.4. In Vitro Binding Assay of PRAK and DJ-1. pGEX-KGDJ-1 and pET-14b-PRAK were transformed into $E$. coli BL21 strain to produce GST-tagged DJ-1 fusion protein and His-tagged PRAK fusion protein, respectively. GST-DJ-1 was purified with GST-bind resin (Novagen) and eluted by reduced glutathione. His-PRAK was purified with $\mathrm{Ni}$ NTA resin (Qiagen) and eluted by elution buffer $(50 \mathrm{mM}$ $\mathrm{NaH}_{2} \mathrm{PO}_{4}, 300 \mathrm{mM} \mathrm{NaCl}$, and $250 \mathrm{mM}$ imidazole, $\mathrm{pH} 8.0$ ). After incubation with either GST-DJ-1 fusion protein or GST, His-PRAK fusion protein was pulled down with Ni-NTA beads, and the precipitate was separated by SDS-PAGE.

2.5. In Vitro DJ-1 Phosphorylation Assay. GST-DJ-1, HisPRAK, and His-p38 fusion proteins were purified as described above. GST-DJ-1 was coincubated with either HisPRAK or His-p38 in the kinase assay buffer containing $25 \mathrm{mM}$ Tris- $\mathrm{HCl}$ ( $\mathrm{pH} 7.5$ ), $5 \mathrm{mM} \beta$-glycerophosphate, $2 \mathrm{mM}$ DTT, $0.1 \mathrm{mM} \mathrm{Na}_{3} \mathrm{VO}_{4}, 10 \mathrm{mM} \mathrm{MgCl}$, and $2 \mu \mathrm{M}$ ATP (PhosphoDetect phosphoserine detection kit, Calbiochem) at $37^{\circ} \mathrm{C}$ for $1 \mathrm{hr}$. The samples were then separated by SDS-PAGE, transferred onto nitrocellulose membranes, and probed with anti-Ser phosphorylation antibody (Calbiochem).

2.6. Cell Cultures and Transfection. Human HEK293, NIH3T3, Hela, PRAK ${ }^{+/+}$, and PRAK ${ }^{-/-}$MEF cells (kindly provided by Dr. Jiahuai Han, The Scripps Research Institute, La Jolla) were maintained at $37^{\circ} \mathrm{C}$ in DMEM supplemented with $10 \%$ FCS, penicillin (100 units $/ \mathrm{mL})$, streptomycin sulfate $(100 \mu \mathrm{g} / \mathrm{mL})$, and glutamine $(2 \mathrm{mM})$. All culture medium and reagents used for cell cultures were purchased from Invitrogen. For immunoprecipitation experiment, 
either HEK293 cells or NIH3T3 cells were cotransfected with pcDNA3-HA-PRAK and pcDNA3-Flag-DJ-1 plasmids for 24 hrs using Lipofectamine 2000 (Invitrogen) according to the manufacturer's instructions. For immunocytochemistry, NIH3T3 cells were cotransfected with either plasmids of pcDNA3-HA-PRAK and pEGFP-DJ-1 or plasmids of pCDNA3-HA-PRAK and pcDNA3-Flag-DJ-1 for $24 \mathrm{hrs}$ using Lipofectamine 2000 (Invitrogen). For FRET assay, Hela cells were cotransfected with pECFP-DJ-1 and pEYFP-PRAK plasmids for 24 hrs using Lipofectamine 2000 (Invitrogen).

2.7. Immunoprecipitation and Immunoblotting. After transfection, human HEK293 cells were lysed in lysis buffer containing $150 \mathrm{mM} \mathrm{NaCl}, 1 \mathrm{mM}$ EDTA, $1 \mathrm{mM}$ EGTA, 1\% Triton X-100, $2.5 \mathrm{mM}$ sodium pyrophosphate, $1 \mathrm{mM} \beta$ glycerolphosphate, $1 \mathrm{mM} \mathrm{Na} \mathrm{VO}_{4}$, and a mixture of protease inhibitors and phosphatase inhibitors (Roche). Equal amounts of extracted protein were mixed with $10 \mu \mathrm{L}$ antiFlag M2 beads (Sigma) and incubated on ice for $6 \mathrm{hrs}$. The samples were spun briefly and washed five times with lysis buffer containing $0.1 \%$ Tween-20. Loading buffer $(20 \mu \mathrm{L})$ was added to each sample and boiled for $5 \mathrm{~min}$. The samples were then separated by SDS-PAGE, transferred onto nitrocellulose membranes, and probed with either anti-HA antibody (Cell Signaling Technology) or anti-Flag M2 antibody (Stratagene).

$\mathrm{PRAK}^{+/+}$cells and PRAK ${ }^{-/-}$cells were treated with $\mathrm{H}_{2} \mathrm{O}_{2}(300 \mu \mathrm{M})$ for different time periods, and nonstimulated Hela cells were lysed as described above. Protein A/G beads $(20 \mu \mathrm{L})$ (sigma) were incubated with $2 \mu \mathrm{g}$ anti-DJ-1 antibody (Abcam), $2 \mu \mathrm{g}$ anti-PRAK antibody (BD Biosciences), or $2 \mu \mathrm{g}$ nonspecific IgG antibody (BD Biosciences) at $4^{\circ} \mathrm{C}$ for $6 \mathrm{hrs}$, spun briefly, and washed five times with lysis buffer containing $0.1 \%$ Tween-20. Equal amounts of extracted protein from $\mathrm{PRAK}^{+/+}$cells, $\mathrm{PRAK}^{-/-}$cells, and Hela cells were incubated with $20 \mu \mathrm{L}$ protein $\mathrm{A} / \mathrm{G}$ beads coupled with antiDJ-1 antibody, anti-PRAK antibody, or IgG on ice for $6 \mathrm{hrs}$. The samples were spun briefly and washed five times with lysis buffer containing $0.1 \%$ Tween-20. Loading buffer $(20 \mu \mathrm{L})$ was added to each sample and boiled for $5 \mathrm{~min}$. The samples were then subjected to immunoblot analysis with anti-Ser phosphorylation antibody (Calbiochem), anti-DJ-1 antibody (Abcam), or anti-PRAK antibody (BD Biosciences).

NIH3T3 cells were lysed after transfection as described above. The resultant lysates were centrifuged and supernatants containing the cytoplasmic proteins were collected. For nuclear protein extraction, the pellets were further lysed in nuclear extraction buffer containing $20 \mathrm{mM}$ Hepes, pH7.9, $420 \mathrm{mM} \mathrm{NaCl}, 1.5 \mathrm{mM} \mathrm{MgCl}_{2}, 0.2 \mathrm{mM}$ EDTA, $1 \mathrm{mM}$ DTT, $25 \%$ glycerol, and a mixture of protease inhibitors and phosphatase inhibitors (Roche). Equal amounts of protein extracted from either cytoplasm or nucleus were subjected to immunoblot analysis.

2.8. Immunofluorescence Assay. NIH3T3 cells were cotransfected with pcDNA-HA-PRAK, pcDNA3-Flag-DJ-1, and PEGFP-DJ-1 for $24 \mathrm{hrs}$. PRAK ${ }^{+/+}$cells and $\mathrm{PRAK}^{-/-}$ cells were starved for $48 \mathrm{hrs}$ and were further challenged with $\mathrm{H}_{2} \mathrm{O}_{2}(300 \mu \mathrm{M})$ for 6 hrs. Cells were fixed in $4 \%$ paraformaldehyde for $10 \mathrm{~min}$, washed twice with PBS, and permeabilized with $0.1 \%$ sodium tetrahydroborate for $5 \mathrm{~min}$. After being washed three times with PBST (PBS + $0.2 \%$ Triton X-100) and blocked with 3\% BSA for $1 \mathrm{hr}$, cells were incubated with the indicated antibodies diluted in 3\% BSA at room temperature for $1 \mathrm{hr}$ and washed three times with PBST. Cells were further incubated with the indicated secondary antibodies diluted in 3\% BSA at room temperature for $1 \mathrm{hr}$ and washed three times with PBST. Cell nucleus was stained with $10 \mu \mathrm{M}$ DAPI. Fluorescent images were recorded and analyzed using a fluorescence microscope (DMRA2, Leica) equipped with FW4000 software.

2.9. FRET Analysis. Hela cells were cotransfected with pECFP-DJ-1 and pEYFP-PRAK using Lipofectamine 2000 (Invitrogen). The live cells were imaged using an inverted fluorescence microscope (Zeiss Axiovert 200 M) $36 \mathrm{hrs}$ after transfection. The donor fluorophore (CFP) was excited at $436 / 25 \mathrm{~nm}$ and fluorescence emission was detected in a bandwidth of $480 / 40 \mathrm{~nm}$ (CFP channel), whereas the acceptor fluorophore (YFP) was excited at 500/25 nm and fluorescence emission was detected in a bandwidth of $535 / 30 \mathrm{~nm}$ (YFP channel). FRET excitation was conducted at $436 / 25 \mathrm{~nm}$ and fluorescence emission was detected in a bandwidth of 535/30 nm (FRET channel). To correct fluorescence bleed through into the FRET channel, cells transfected with either pECFP-DJ-1 alone or pEYFP-PRAK alone were used to determine the donor or the acceptor correction factor. Images of CFP-DJ-1 and YFP-PRAK expression in cotransfected cells were sequentially acquired with the donor (CFP) channel, acceptor (YFP) channel, and FRET channel under identical conditions. The image obtained with the FRET channel was evaluated using Carl Zeiss AxioVision FRET 4.6 software and values of FRET were calculated as described previously [28].

2.10. Cell Viability Assay. $\mathrm{PRAK}^{+/+}$and $\mathrm{PRAK}^{-/-}$cells were plated in 96-well tissue culture plates $\left(2.5 \times 10^{4}\right.$ cells per well) and exposed to $\mathrm{H}_{2} \mathrm{O}_{2}(300 \mu \mathrm{M})$ for different time periods. Cell viability was quantified using a Cell Titer 96 Aqueous One solution cell proliferation assay kit (Promega) with a HTS7000 Bio-Assay Reader (Perkin Elmer).

2.11. Statistical Analysis. All data are expressed as mean \pm SD. Statistical analysis was performed by the Student's $t$-test and ANOVA. Differences were judged statistically significant when the $P$ value was less than 0.05 .

\section{Results}

3.1. Interaction of DJ-1 and PRAK in Yeast. To screen the PRAK-binding proteins, we amplified a full-length human PRAK cDNA (1415 bp) from pcDNA3-HA-PRAK by PCR and subcloned it into the pGBKT7 vector. pGBKT7-PRAK was transformed into the yeast strain AH109 and placed on SD/ -Trp plates, which expresses Myc-DBD-PRAK fusion protein as confirmed by Western blot analysis (Figure 1(a)).

A Gal4-based yeast two-hybrid system was used to identify proteins that interact with PRAK. The pGBKT7-PRAK 


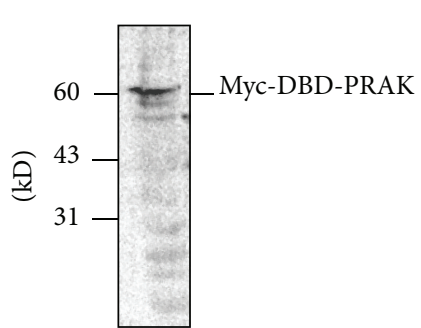

(a)

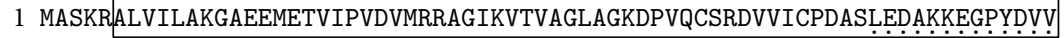

71 VLPGGNLGAQNLSESAAVKEILKEQENRKGLIAAICAGPTALLAHEIGFGSKVTTHPLAKDKMMNGGHYT

141 YSENRVEKDGLILTSRGPGTSFEFALAIVEATNGGKEVAQQ̣KAPLVLKD 189

Conserved GATase 1 domain

... Coding sequence of the positive clone

(b)

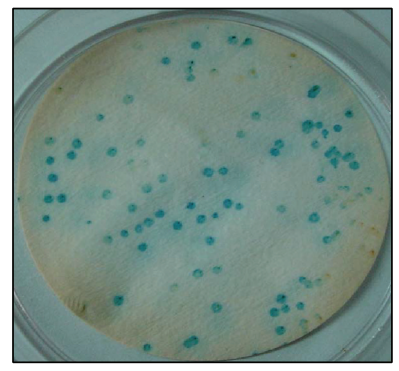

(c)

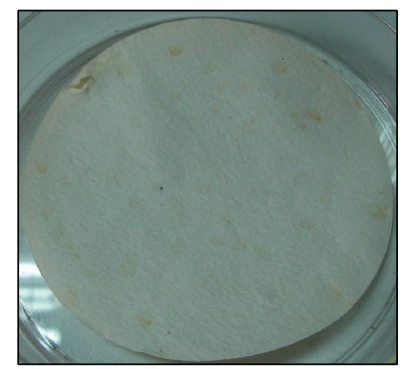

(d)

FIGURE 1: Interaction of DJ-1 and PRAK in yeast. (a) Myc-DBD-PRAK fusion protein detected by Western blot using an antibody against Myc. (b) The coding sequence of a positive clone was identical to the C-terminal (174 567 bp) of Homo sapiens DJ-1. The underdot-lined region represents the coding sequence (58-189 aa) of the positive clone that interacts with PRAK. (c) and (d) $\beta$-Galactosidase activity of yeast clones either expressing AD-DJ-1 and DBD-PRAK fusion proteins (c) or expressing AD-DJ-1 and DBD proteins (d) on SD/-Ade/-His/-Leu/Trp/X- $\alpha$-gal plates.

plasmid was transformed into the yeast strain AH109 as the bait and a human heart cDNA library was previously transformed into the yeast strain Y187 as the prey. Approximately $1 \times 10^{6}$ transformants were screened and a total of seven positive clones were obtained. NCBI blast results revealed that clone 4 was identical to the coding sequence (58-189 aa) of human DJ-1 (Figure 1(b)).

To further test the interaction between DJ-1 and PRAK, yeast strains AH109 expressing active domain- (AD-) fused DJ-1 and Y187 expressing DNA binding domain- (DBD-) fused PRAK were mixed, mated for $24 \mathrm{hrs}$, and plated on SD/-Leu/-Trp plates. After the yeast colonies were transferred onto SD/-Ade/-His/-Leu/-Trp/X- $\alpha$-gal plates, $\beta$ galactosidase activity was measured to assess the interaction between DJ-1 and PRAK. Yeasts transformed with both DBD-PRAK and AD-DJ-1 expressed the LacZ phenotype (Figure 1(c)), whereas yeasts transformed with $\mathrm{DBD}$ and $\mathrm{AD}$ DJ-1 failed to show any LacZ activity (Figure 1(d)), confirming that DJ-1 interacts with PRAK, but not DBD, in yeast.

3.2. In Vitro and In Vivo Interaction between DJ-1 and PRAK. Glutathione S-transferase- (GST-) tagged DJ-1 and His-tagged PRAK fusion proteins were expressed in E. coli, respectively. Purified His-PRAK fusion protein was mixed with either GST-DJ-1 fusion protein or GST and further pulled down by nickel-nitrilotriacetic acid (Ni-NTA) precipitation and separated by SDS-PAGE. As shown in Figures 2(a) and 2(b), His-PRAK specifically bound to GST-DJ-1, but not GST, in vitro.
To assess the interaction of PRAK with DJ-1 in vivo, human HEK293 cells were transfected with pcDNA3-HAPRAK plasmid with or without pcDNA3-Flag-DJ-1 plasmid. Twenty-four hours after transfection, cell extracts were prepared and subjected to immunoprecipitation with an antiFlag antibody. The precipitates were then blotted with an antiHA antibody. HA-PRAK was coprecipitated with Flag-DJ-1 in cells cotransfected with Flag-DJ-1 and HA-PRAK, but not in cells transfected with HA-PRAK alone (Figure 2(c)), indicating that PRAK specifically binds to DJ-1 in HEK293 cells.

To examine whether PRAK binds to DJ-1 under physiological conditions, cell extracts prepared from Hela cells were immunoprecipitated with an anti-PRAK antibody or a nonspecific IgG, and the precipitates were further immunoblotted against an anti-DJ-1 antibody. The anti-PRAK antibody did precipitate PRAK, and furthermore, DJ-1 was detected in the precipitates with the anti-PRAK antibody but not with a control IgG (Figure 2(d)). These data clearly indicate that there is a constitutive binding of PRAK with DJ-1 in nonstimulated cells.

To further confirm the above finding in live cells, we constructed a pair of plasmids encoding either CFP-DJ-1 or YFP-PRAK to perform a fluorescence resonance energy transfer (FRET) assay. Hela cells were cotransfected with pECFP-DJ-1 and pEYFP-PRAK plasmids, and the coexpression of CFP and YFP was evaluated by FRET. As shown in Figure 2(e), cells cotransfected with both CFP-DJ-1 and YFPPRAK depicted a distinct color-coded FRET region, with the efficiency ranging from $15 \%$ to $17 \%$, which illustrates 


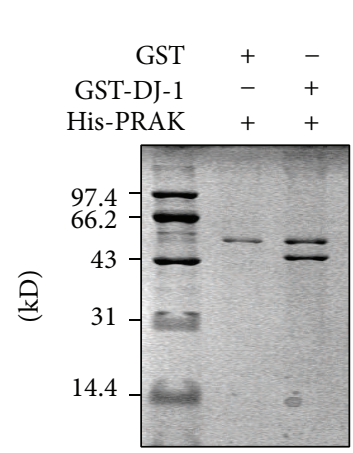

(a)
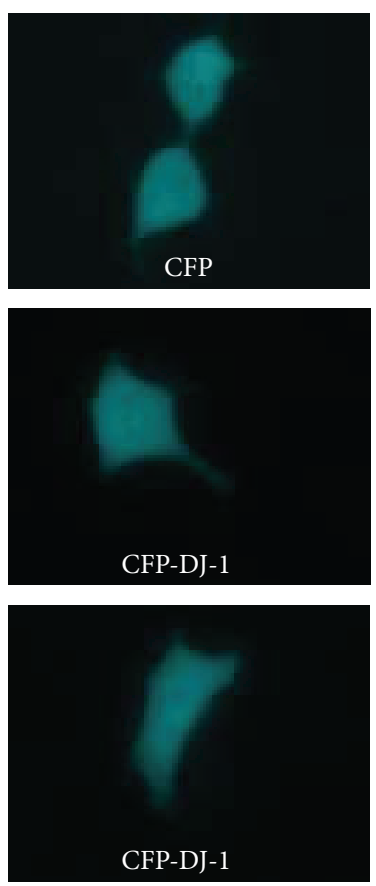

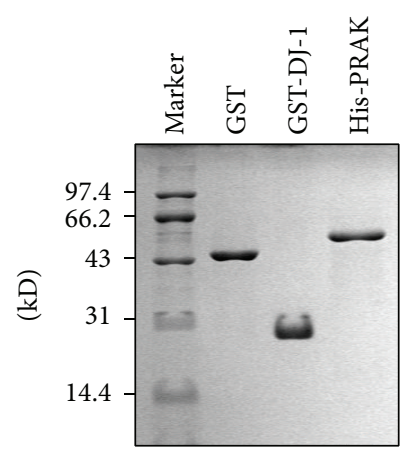

(b)
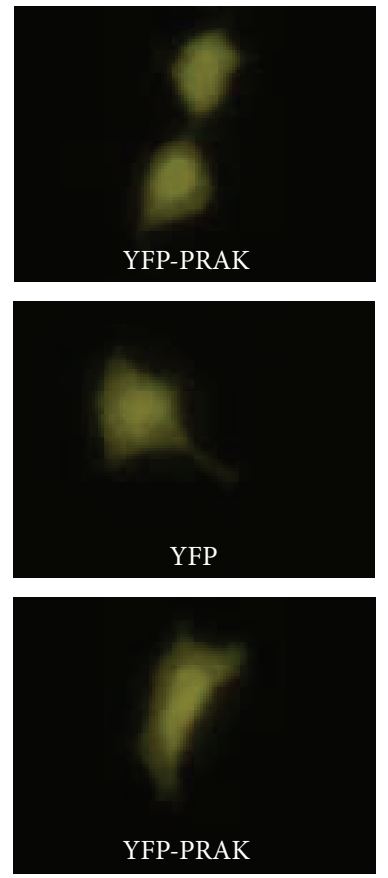

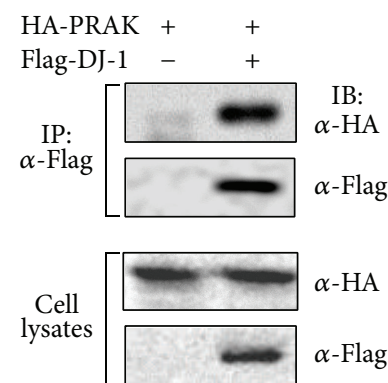

(c)
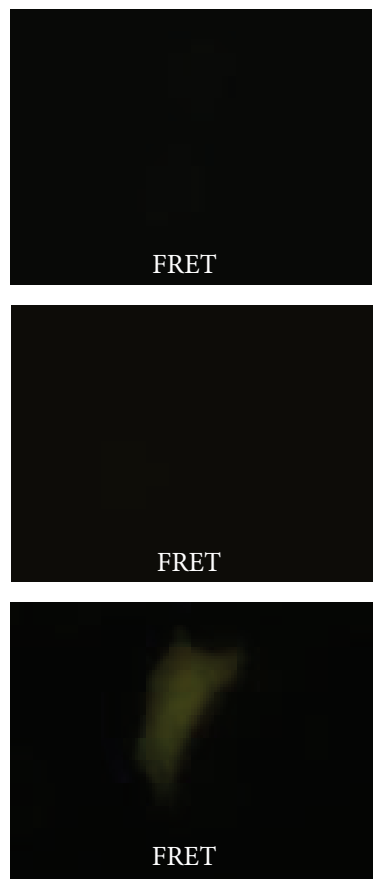

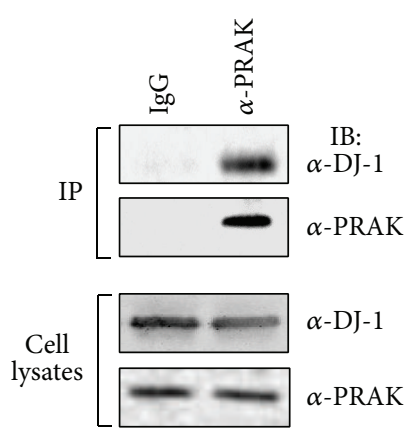

(d)
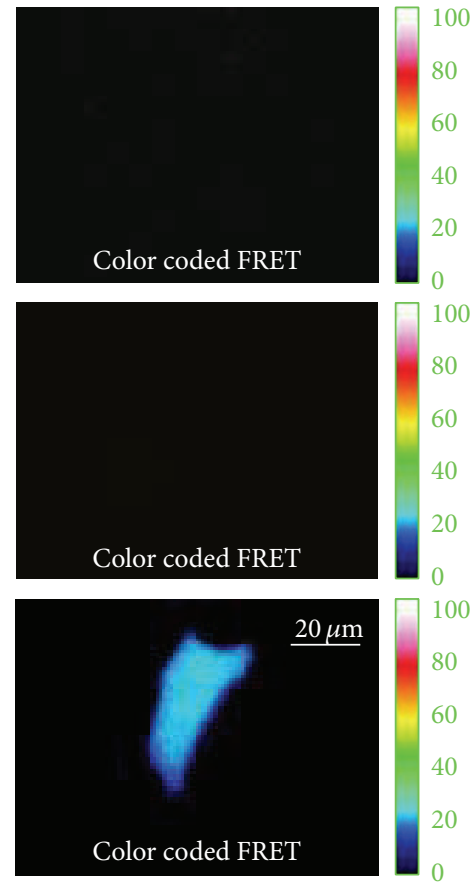

(e)

FIGURE 2: Interaction between PRAK and DJ-1 in vitro and in vivo. (a) SDS-PAGE analysis of interaction of His-PRAK with either GST-DJ1 or GST in vitro. The protein bands are visualized by Coomassie blue staining. (b) The equal input of His-PRAK, GST-DJ-1, and GST on SDS-PAGE. (c) HEK293 cells were cotransfected with pcDNA3/HA-PRAK and pcDNA3/Flag-DJ-1. pcDNA3-Flag was used as the control. Cell lysates were precipitated with anti-flag M2 beads, and both immunoprecipitates (upper) and cell lysates (lower) were immunoblotted with either anti-HA or anti-Flag antibodies. (d) Cell lysates from naive Hela cells were precipitated with protein A/G beads coupled with IgG (left) or anti-PRAK antibody (right). Both immunoprecipitates (upper) and cell lysates (lower) were immunoblotted with either anti-DJ-1 or anti-PRAK antibodies. (e) CFP-DJ-1 and YFP-PRAK were coexpressed in Hela cells followed by observation with different fluorescence channels CFP, YFP, and FRET. The FRET efficiency depicted as a color-coded scale ranging from 0 to $100 \%$. Coexpression of either CFP and YFP-PRAK or YFP and CFP-DJ-1 in Hela cells was used as the control.

an interaction between PRAK and DJ-1. In contrast, cells cotransfected with either CFP and YFP-PRAK or YFP and CFP-DJ-1 failed to display any significant FRET (Figure 2(e)).

\subsection{Colocalization between PRAK and DJ-1. To examine the} intracellular localization of PRAK and DJ-1, NIH3T3 cells were cotransfected with pcDNA3-HA-PRAK and pEGFPDJ-1 and further stained with an anti-HA antibody and visualized with a Texas red-conjugate secondary antibody. We observed that exogenously introduced HA-PRAK colocalized with GFP-DJ-1 in the nuclei of the NIH3T3 cells (Figure 3(a)).
It has been reported that, in the normal circumstance, endogenous PRAK is mainly located in the cytoplasm of the cells [26], whereas the location of endogenous DJ-1 is cell cycle related and present in both cytoplasm and nucleus [27]. We stained PRAK $^{+/+}$cells with antibodies against PRAK and DJ-1 and FITC- and Texas red-conjugated secondary antibodies, to assess whether endogenous PRAK colocalized with endogenous DJ-1; however, there was no obvious colocalization between PRAK and DJ-1 observed in the nucleus (Figure 3(b)). In contrast, when $\mathrm{PRAK}^{+/+}$cells were synchronized by serum starvation for $48 \mathrm{hrs}$ and then 


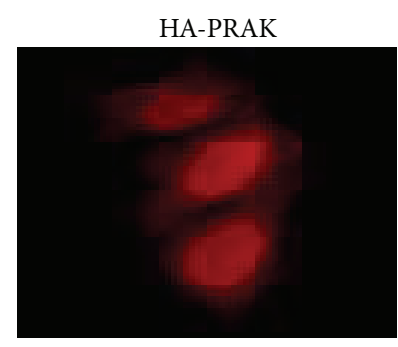

PRAK
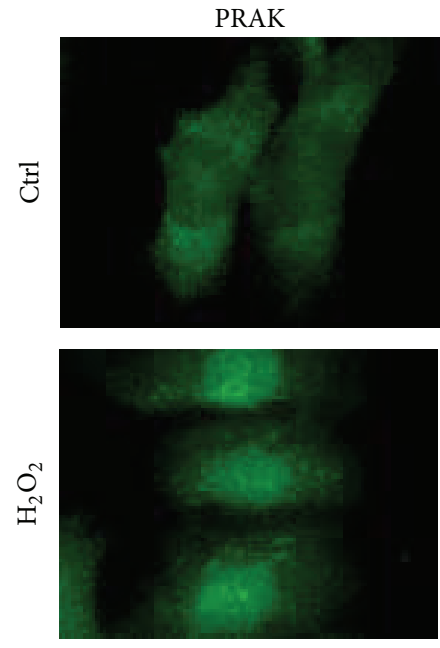

GFP-DJ-1
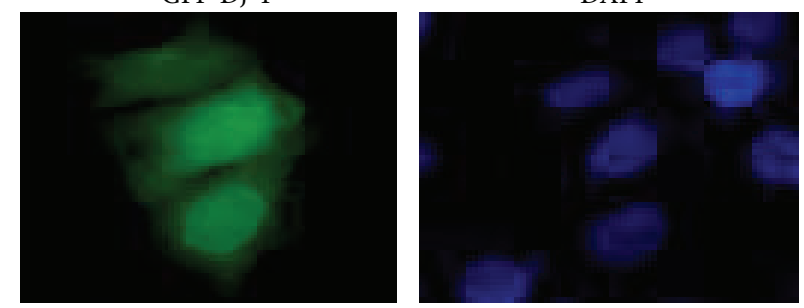

(a)
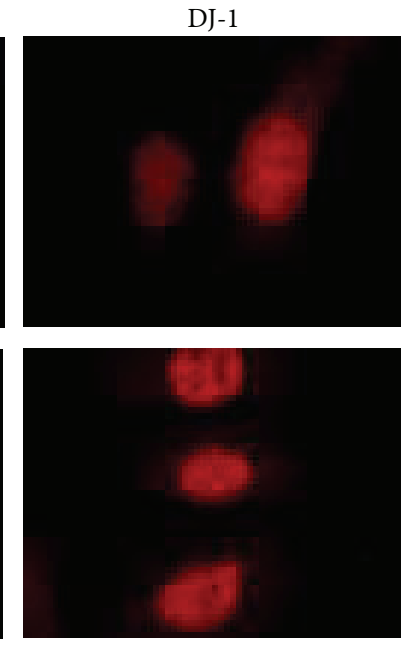

DAPI
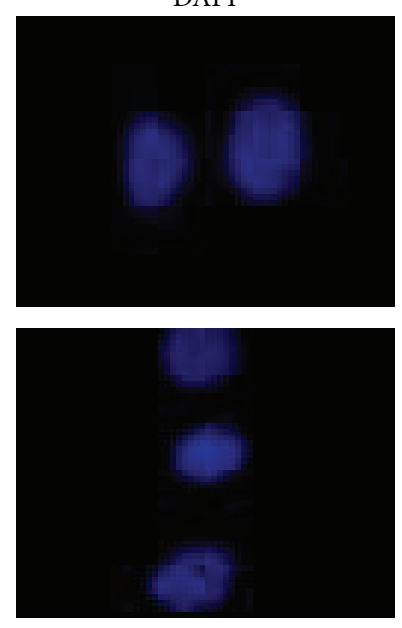

Merge

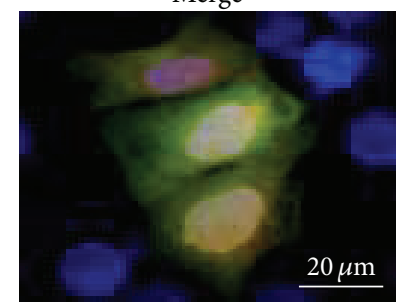

Merge
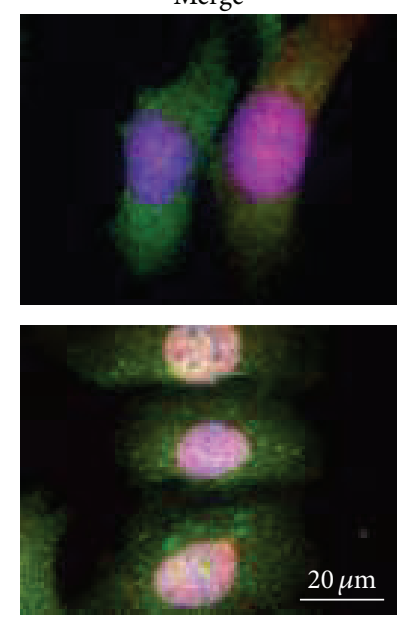

(b)

FIGURE 3: Intracellular colocalization between PRAK and DJ-1. (a) NIH3T3 cells were cotransfected with pcDNA3-HA-PRAK and pEGFPDJ-1, stained with an anti-HA antibody and visualized with a Texas red-conjugated secondary antibody. (b) Naive PRAK ${ }^{+/+}$cells (upper) or $\mathrm{PRAK}^{+/+}$cells synchronized by serum starvation for $48 \mathrm{hrs}$ and treated with $300 \mu \mathrm{M} \mathrm{H}_{2} \mathrm{O}_{2}$ for 6 hrs (lower) were stained with the primary antibodies against PRAK and DJ-1 and visualized with FITC- and Texas red-conjugated secondary antibodies. Nuclei were stained with DAPI. Scale bar $=20 \mu \mathrm{m}$.

treated with $300 \mu \mathrm{M}$ of $\mathrm{H}_{2} \mathrm{O}_{2}$ for 6 hrs, we did observe the colocalization of endogenous PRAK with DJ-1 in the nucleus (Figure 3(b)), indicating that, in response to oxidative stress, endogenous PRAK moves into the nucleus and colocalizes with DJ-1.

3.4. The Effect of PRAK on Subcellular Localization and Phosphorylation of DJ-1. NIH3T3 cells were transfected with pcDNA3-Flag-DJ-1, in combination with either pcDNA3HA-PRAK or pcDNA-HA. Western blot analysis of cytoplasmic and nuclear extracts revealed that Flag-DJ-1 was mainly located in the cytoplasm when it was transfected alone; however, Flag-DJ-1 distributed in both cytoplasm and nucleus when it was cotransfected with HA-PRAK (Figures 4(a) and 4(b)), suggesting that overexpression of PRAK leads to a shift of DJ-1 from the cytoplasm to the nucleus. This finding was further supported by the results from fluorescent micrographs. GFP-DJ-1 was observed in the cytoplasm and nucleus when cells were transfected with pcDNA3-EGFP-DJ1 alone (Figure 4(c)); however, more GFP-DJ-1 aggregated in the nucleus when cells were cotransfected with both pcDNA3-EGFP-DJ-1 and pcDNA3-HA-PRAK (Figure 4(c)).
Next, we examined the localization of endogenous DJ-1 in $\mathrm{PRAK}^{+/+}$and $\mathrm{PRAK}^{-/-}$cells after the cells were synchronized by serum starvation for $48 \mathrm{hrs}$ and treated with $300 \mu \mathrm{M}$ of $\mathrm{H}_{2} \mathrm{O}_{2}$ for 6 hrs. In PRAK ${ }^{+/+}$cells, endogenous DJ-1 mainly located in the nucleus even after the cells were treated with $\mathrm{H}_{2} \mathrm{O}_{2}$ for $6 \mathrm{hrs}$ (Figures 5(a) and 5(c)). However, in nonstimulated $\mathrm{PRAK}^{-/-}$cells, more endogenous DJ-1 appeared in the cytoplasm when compared with nonstimulated $\mathrm{PRAK}^{+/+}$ cells (Figures 5(b) and 5(d)). Furthermore, most endogenous DJ-1 in PRAK ${ }^{-/-}$cells translocated into the cytoplasm from the nucleus after the cells being treated with $\mathrm{H}_{2} \mathrm{O}_{2}$ for $6 \mathrm{hrs}$ (Figures 5(b) and 5(d)).

To assess whether PRAK can directly phosphorylate DJ1, GST-tagged DJ-1 was incubated with His-tagged PRAK or p38 fusion proteins. Coincubation of His-PRAK but not Hisp38 with GST-DJ-1 induced phosphorylation of DJ-1 (Figures 6(a) and 6(b)). To further validate our in vitro finding, $\mathrm{PRAK}^{+/+}$and $\mathrm{PRAK}^{-/-}$cells were treated with $300 \mu \mathrm{M} \mathrm{H}_{2} \mathrm{O}_{2}$ for different time periods. In contrast to $\mathrm{PRAK}^{-/-}$cells, $\mathrm{H}_{2} \mathrm{O}_{2}$-challenged $\mathrm{PRAK}^{+/+}$cells displayed a substantially increased expression of phosphorylated DJ-1 (Figures 6(c) and 6(d)), indicating that PRAK phosphorylates DJ-1 in response to $\mathrm{H}_{2} \mathrm{O}_{2}$-induced oxidative stress. 


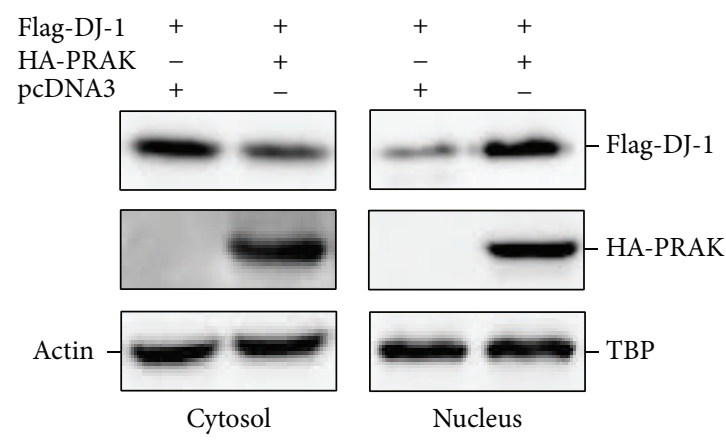

(a)

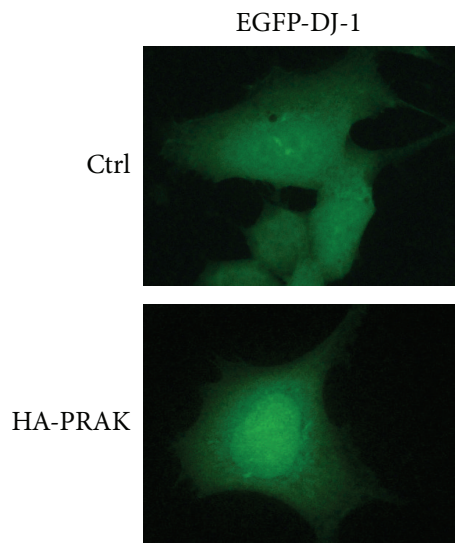

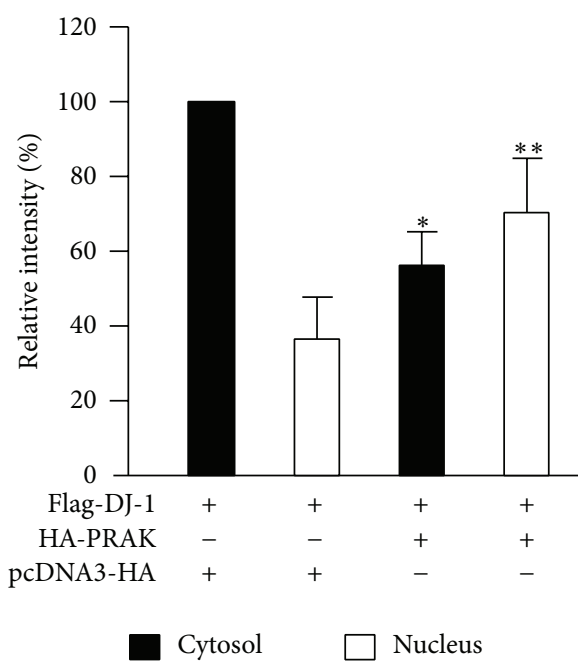

(b)

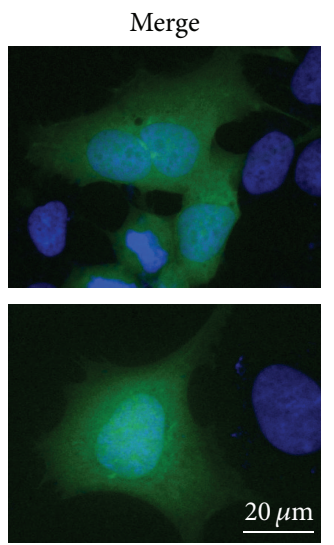

(c)

FIGURE 4: Overexpression of PRAK influences the intracellular distribution of DJ-1. (a) NIH3T3 cells were cotransfected with pcDNA3Flag-DJ-1 and pcDNA3-HA-PRAK. pcDNA3-HA was used as the control. Both cytosolic and nuclear fractions of cell lysates were analyzed by Western blot with anti-Flag or anti-HA antibodies. TATA binding protein (TBP) and $\beta$-actin were used as internal controls for nuclear and cytosolic proteins, respectively. (b) The relative intensities of Flag-DJ-1 protein bands from Western blot were analyzed and data are expressed as the mean $\pm \mathrm{SD}$ of four separate experiments. ${ }^{*} P<0.05$ compared with Flag-DJ-1 in the cytosol fraction from cells transfected with pcDNA3-HA; ${ }^{* *} P<0.05$ compared with Flag-DJ-1 in the nuclear fraction from cells transfected with pcDNA3-HA. (c) NIH3T3 cells were cotransfected with pcDNA3-EGFP-DJ-1 and pcDNA3-HA-PRAK or pcDNA3-EGFP-DJ-1 and pcDNA3-HA as the control. Nuclei were stained with DAPI. Scale bar $=20 \mu \mathrm{m}$.

3.5. PRAK Facilitates DJ-1 to Sequester Daxx in the Nucleus and Prevent Cell Death. Previous studies reported that Daxx interacts with apoptosis signal-regulating kinase 1 (ASK1) and causes activation of this kinase, which subsequently triggers cell death [29], whereas DJ-1 can hamper the interaction between Daxx and ASK1 by recruiting Daxx in the nucleus, thereby inhibiting ASK1 activation and cell death [30]. We found that endogenous DJ-1 normally located in the nuclei of $\mathrm{PRAK}^{+/+}$cells; however, in PRAK ${ }^{-/-}$cells, DJ-1 translocated from the nucleus into the cytoplasm following $\mathrm{H}_{2} \mathrm{O}_{2}$ treatment (Figure 5). Based on these findings, we hypothesized that, under oxidative stress, DJ-1, in the absence of PRAK, is unable to sequester Daxx in the nucleus, and more Daxx translocate into the cytoplasm, thereby causing ASK1 activation and cell death. To confirm this, we assessed
DJ-1 and Daxx localization in both $\mathrm{PRAK}^{+/+}$and $\mathrm{PRAK}^{-/-}$ cells following $\mathrm{H}_{2} \mathrm{O}_{2}$ treatment. In PRAK ${ }^{+/+}$cells, DJ-1 and Daxx colocalized in the nucleus (Figures 7(a) and 7(c)). After the cells were treated with $300 \mu \mathrm{M} \mathrm{H} \mathrm{H}_{2} \mathrm{O}_{2}$ for $6 \mathrm{hrs}$, DJ-1 still remained in the nucleus and the majority of Daxx was kept in the nucleus despite a small amount of Daxx which translocated into the cytoplasm (Figures $7(\mathrm{a})$ and $7(\mathrm{c})$ ). In contrast, most DJ-1 in PRAK ${ }^{-/-}$cells translocated into the cytoplasm in response to the $\mathrm{H}_{2} \mathrm{O}_{2}$ challenge and failed to sequester Daxx in the nucleus (Figures $7(\mathrm{~b})$ and $7(\mathrm{~d})$ ). As a result, Daxx translocated from the nucleus into the cytoplasm (Figures 7(b) and 7(d)).

To further examine the influence of cytoplasmic translocation of Daxx, observed in $\mathrm{H}_{2} \mathrm{O}_{2}$-treated PRAK ${ }^{-/-}$cells, on cell survival, we incubated both $\mathrm{PRAK}^{+/+}$and $\mathrm{PRAK}^{-/-}$ 

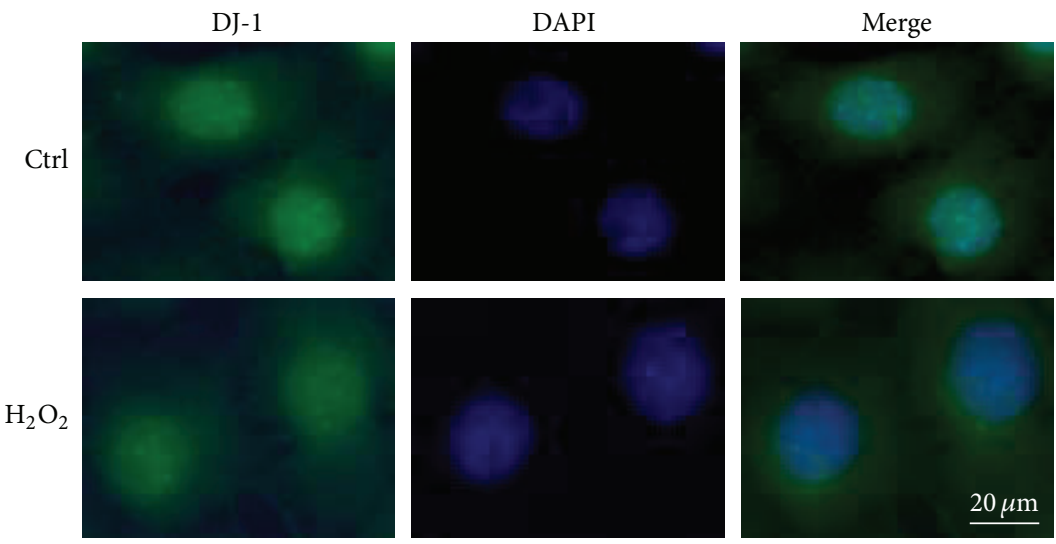

(a)
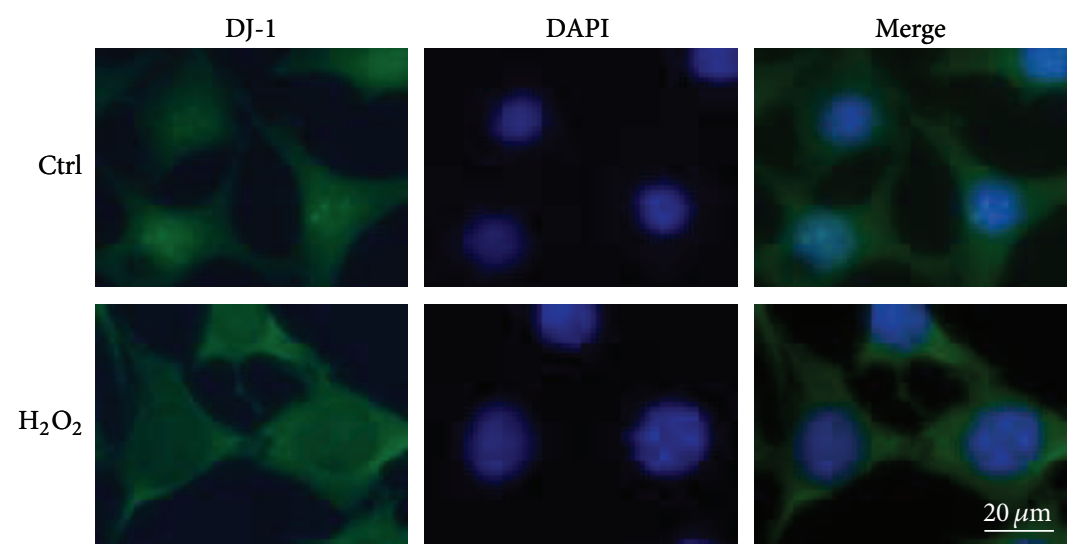

(b)

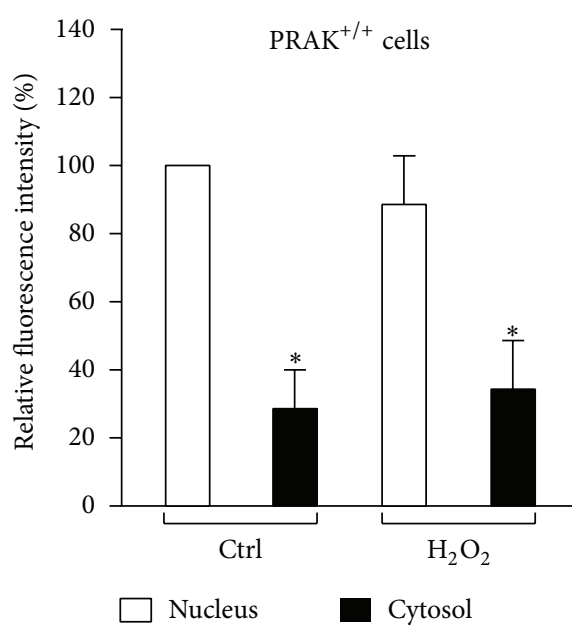

(c)

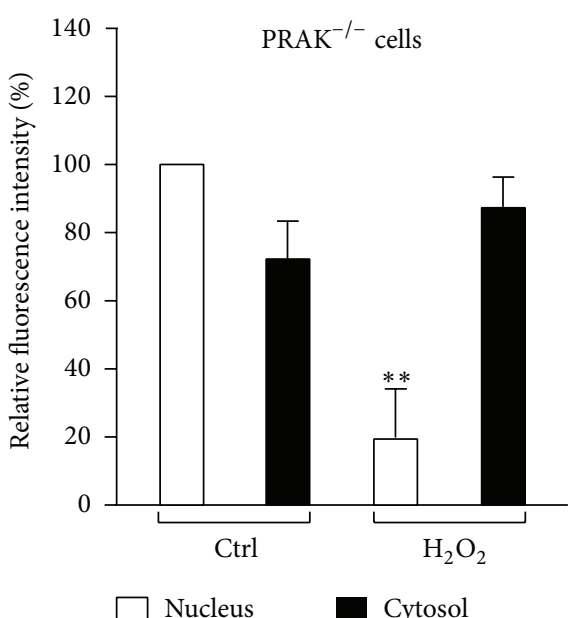

(d)

FIGURE 5: Effect of PRAK on DJ-1 nuclear localization under oxidative stress. (a) PRAK ${ }^{++}$cells synchronized by serum starvation for $48 \mathrm{hrs}$ and treated with culture medium (upper) or $300 \mu \mathrm{M} \mathrm{H}_{2} \mathrm{O}_{2}$ (lower) for 6 hrs were stained with anti-DJ-1 antibody. (b) PRAK ${ }^{-/-}$cells synchronized by serum starvation for $48 \mathrm{hrs}$ and treated with culture medium (upper) or $300 \mu \mathrm{M} \mathrm{H}_{2} \mathrm{O}_{2}$ (lower) for 6 hrs were stained with anti-DJ-1 antibody. Nuclei were stained with DAPI. Scale bar $=20 \mu \mathrm{m}$. (c) and (d). The nuclear and cytoplasmic fluorescence intensities of DJ-1 in $\mathrm{PRAK}^{+/+}$cells (c) and PRAK ${ }^{-/-}$cells (d) were analyzed. Data are expressed as the mean \pm SD of four separate experiments. ${ }^{*} P<0.05$ compared with DJ-1 in the nucleus of control or $\mathrm{H}_{2} \mathrm{O}_{2}$-treated PRAK ${ }^{+++}$cells (c); ${ }^{* *} P<0.05$ compared with DJ-1 in the nucleus of control PRAK $^{-1-}$ cells $(\mathrm{d})$. 

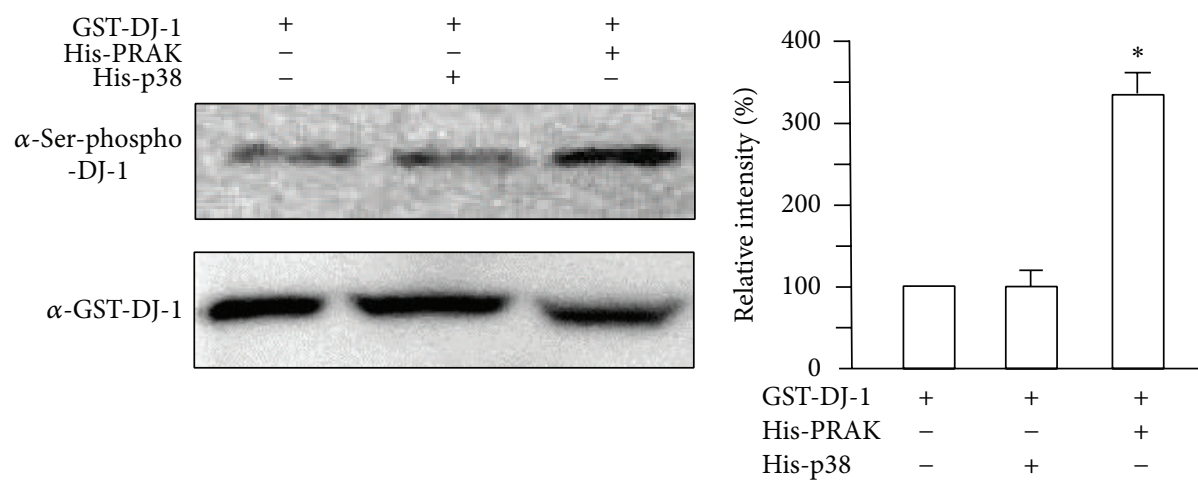

(a)

(b)

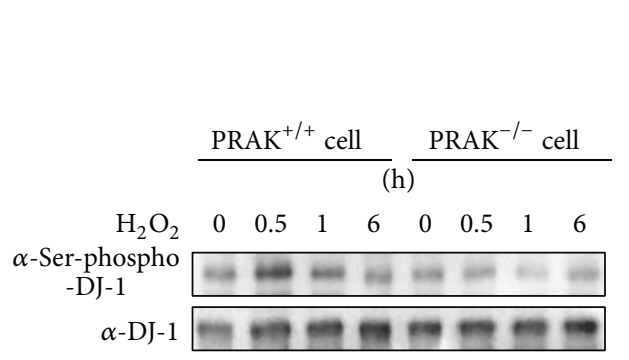

(c)

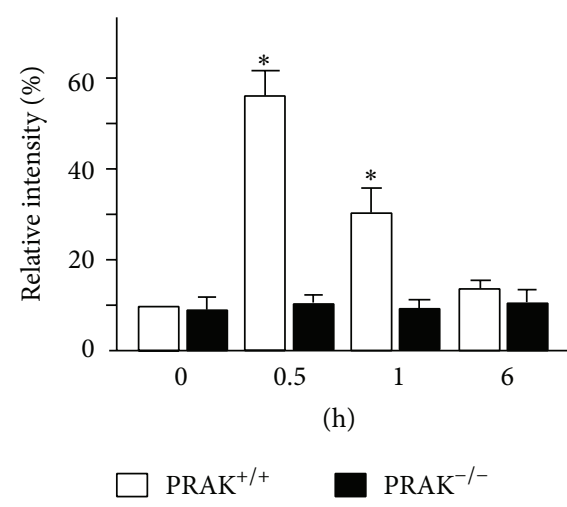

(d)

FIGURE 6: PRAK phosphorylates DJ-1 both in vitro and in vivo. (a) GST-tagged DJ-1 was coincubated with His-tagged PRAK or His-tagged p38 and further analyzed by Western blot. (b) The relative intensities of phosphorylated DJ-1 were analyzed and data are expressed as the mean \pm SD of three separate experiments. ${ }^{*} P<0.05$ compared with GST-DJ-1 coincubated with His-p38. (c) PRAK ${ }^{+/+}$and PRAK ${ }^{-/-}$cells were treated with $300 \mu \mathrm{M} \mathrm{H}_{2} \mathrm{O}_{2}$ for different time periods. The expression of phosphorylated and total DJ-1 was assessed by Western blot analysis. (d) The relative intensities of phosphorylated DJ-1 were analyzed and data are expressed as the mean \pm SD of three separate experiments. ${ }^{* *} P<0.05$ compared with PRAK ${ }^{-/-}$cells.

cells with $300 \mu \mathrm{M} \mathrm{H}_{2} \mathrm{O}_{2}$ for different time periods. As shown in Figure 8, $\mathrm{PRAK}^{-/-}$cells exhibited significantly impaired ability to survive from $\mathrm{H}_{2} \mathrm{O}_{2}$-induced oxidative stress when compared to $\mathrm{PRAK}^{+/+}$cells.

\section{Discussion}

DJ-1, first identified by Nagakubo et al. [27] as a mitogendependent oncogene product, is ubiquitously expressed in almost all human tissues as homodimers and participates in many physiological and pathological processes including tumorigenesis [31-33], fertilization [34, 35], regulation of the androgen receptor [36-40], posttranslational modification of protein SUMO-1, a ubiquitin-like modifier [41], oxidative stress [42-44], and the development of Parkinson's disease [45-49]. However, it is undefined whether DJ-1 is a downstream interacting target for PRAK. In the present study, using a yeast two-hybrid system, we identified that DJ-1 is a potential PRAK interacting partner. A pull-down assay demonstrated that His-PRAK exclusively bound to GSTDI-1. Immunoprecipitation and immunoblotting data from human HEK293 cells revealed that PRAK was coprecipitated with DJ-1 in cells cotransfected with pCDNA3-HA-PRAK and pCDNA3-Flag-DJ-1 plasmids but not in cells transfected with pCDNA3-HA-PRAK alone. In addition, a constitutive binding of endogenous PRAK with DJ-1 was observed in nonstimulated Hela cells as confirmed by immunoprecipitation with anti-PRAK antibody and immunoblotting with antiDJ-1 antibody. Using a FRET-based technique, we further illustrated an interaction between PRAK and DJ-1 in Hela cells. These results clearly demonstrate that PRAK binds to and interacts with DJ-1 both in vitro and in vivo.

It has been shown that endogenous PRAK is mainly located in the cytoplasm, whereas exogenous PRAK predominates in the nucleus [26]. On the other hand, endogenous DJ-1 is present in both cytoplasm and nucleus [27]. However, it is unclear whether PRAK preferentially colocalizes with DJ-1, thus affecting the intracellular distribution of DJ-1. We first examined the intracellular colocalization of either exogenously introduced or endogenous PRAK and DJ-1. We cotransfected NIH3T3 cells with pCDNA3-HA-PRAK and pEGFP-DJ-1 plasmids and observed colocalization of exogenously introduced PRAK with DJ-1 in the nucleus. Although there was no apparent colocalization of endogenous PRAK 

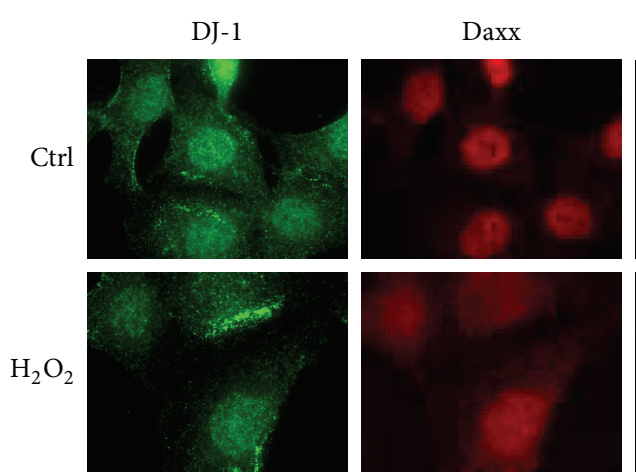

(a)
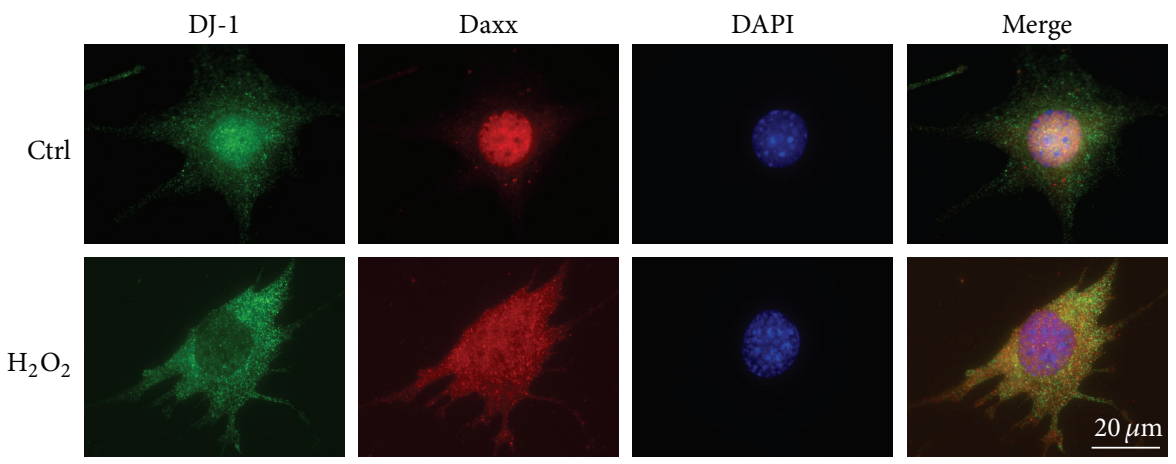

(b)
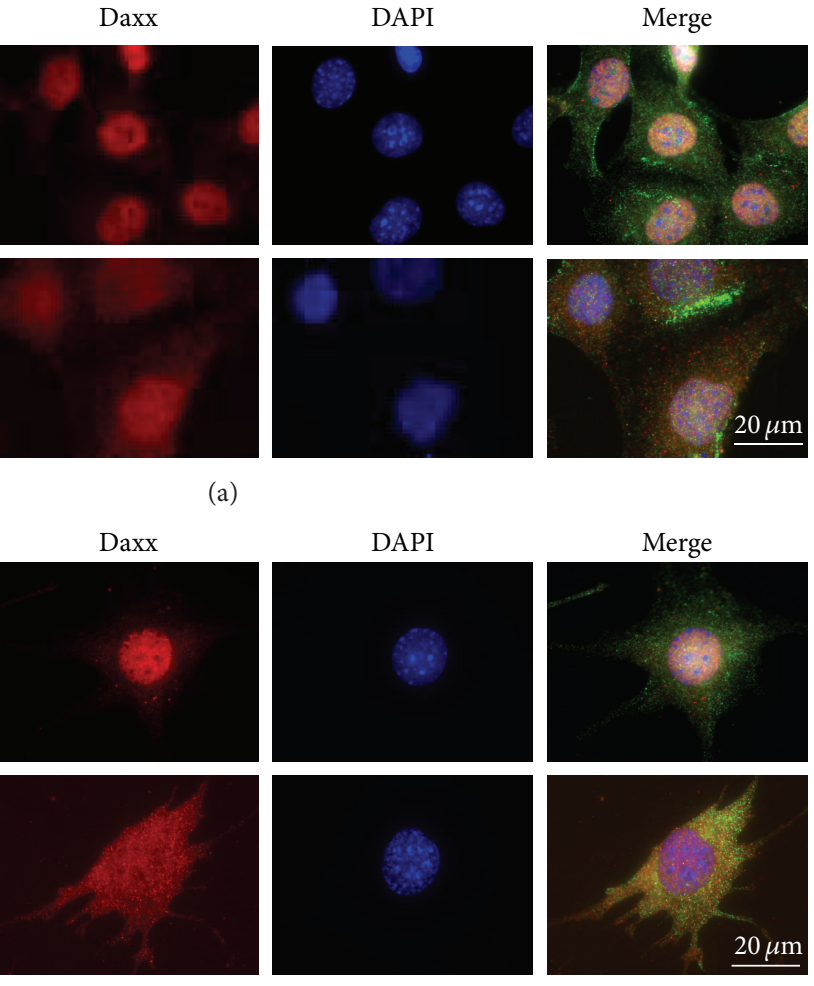

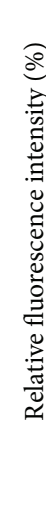

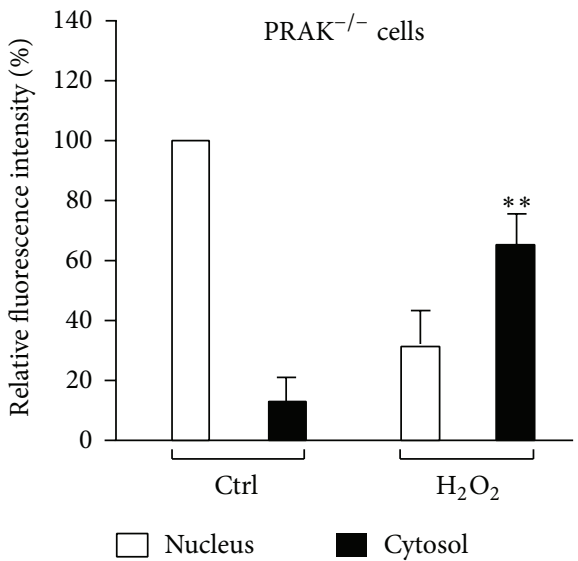

(d)

FIGURE 7: PRAK helps DJ-1 to sequester Daxx in the nucleus. (a) PRAK ${ }^{+/+}$cells synchronized by serum starvation for 48 hrs and treated with culture medium (upper) or $300 \mu \mathrm{M} \mathrm{H}_{2} \mathrm{O}_{2}$ (lower) for $6 \mathrm{hrs}$ were stained with antibodies against DJ-1 and Daxx and further visualized with FITC- and Texas red-conjugated secondary antibodies. (b) PRAK ${ }^{-1-}$ cells synchronized by serum starvation for 48 hrs and treated with culture medium (upper) or $300 \mu \mathrm{M} \mathrm{H}_{2} \mathrm{O}_{2}$ (lower) for $6 \mathrm{hrs}$ were stained with antibodies against DJ-1 and Daxx and further visualized with FITC- and Texas red-conjugated secondary antibodies. Nuclei were stained with DAPI. (c) and (d). The nuclear and cytoplasmic fluorescence intensities of Daxx in PRAK ${ }^{+/+}$cells (c) and PRAK ${ }^{-/}$cells (d) were analyzed. Data are expressed as the mean \pm SD of four separate experiments. ${ }^{*} P<0.05$ compared with Daxx in the nucleus of naive or $\mathrm{H}_{2} \mathrm{O}_{2}$-treated PRAK ${ }^{+/+}$cells (c); ${ }^{* *} \mathrm{P}<0.05$ compared with Daxx in the cytoplasm of naive $\mathrm{PRAK}^{-/-}$cells $(\mathrm{d})$.

with DJ-1 found in nonstimulated cells, we did observe that endogenous PRAK in PRAK ${ }^{+/+}$cells colocalized with DJ-1 in the nucleus in response to $\mathrm{H}_{2} \mathrm{O}_{2}$-induced oxidative stress. To further examine the influence of PRAK on subcellular localization of DJ-1, we transfected NIH3T3 cells with
pcDNA3-Flag-DJ-1 in the presence or absence of pcDNA3HA-PRAK. When cells were transfected with Flag-DJ-1 alone, the exogenously introduced DJ-1 was mainly located in the cytoplasm. However, when cells were cotransfected with both Flag-DJ-1 and HA-PRAK, more exogenously introduced DJ-1 


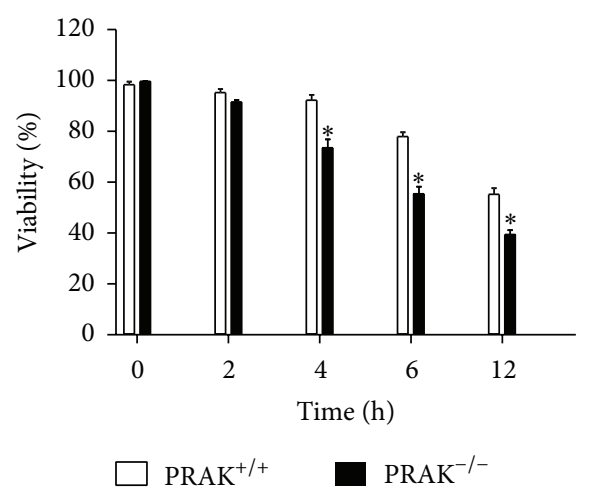

FIGURE 8: Cell viability in $\mathrm{PRAK}^{+/+}$and $\mathrm{PRAK}^{-/-}$cells challenged with $\mathrm{H}_{2} \mathrm{O}_{2}$-induced oxidative stress. $\mathrm{PRAK}^{+/+}$and $\mathrm{PRAK}^{-/-}$cells were treated with $300 \mu \mathrm{M} \mathrm{H}_{2} \mathrm{O}_{2}$ for different time periods. Cell viability was assessed as described in Section 2. Data are expressed as the mean \pm SD of triplicate samples and representative of at least four to six independent experiments. ${ }^{*} P<0.05$ compared with $\mathrm{PRAK}^{+/+}$ cells.

translocated from the cytoplasm into the nucleus. Similarly, endogenous DJ-1 in $\mathrm{PRAK}^{+/+}$cells was mainly located in the nucleus even after the cells were treated with $\mathrm{H}_{2} \mathrm{O}_{2}$ for $6 \mathrm{hrs}$; in contrast, most endogenous DJ-1 in $\mathrm{PRAK}^{-/-}$cells translocated from the nucleus into the cytoplasm in response to $\mathrm{H}_{2} \mathrm{O}_{2}$ challenge. These results demonstrate that PRAK preferentially colocalizes with DJ-1 and helps DJ-1 to localize in the nucleus in response to oxidative stress. On the other hand, it has been reported that DJ-1 can shuttle between cytoplasm and nucleus [27], but it contains no NLS [50], indicating that there must be some other protein(s) which interact with DJ-1 and decide the subcellular localization of DJ-1. Our data support the notion that PRAK is one of such candidates that interacts with DJ-1 and assists its shuttling between nucleus and cytoplasm. It is important to clarify whether interaction of PRAK with DJ-1, in addition to facilitating the intracellular localization of DJ-1, also leads to DJ-1 phosphorylation. Using an in vitro assay system, we found that phosphorylation of DJ-1 was achieved only when GST-DJ-1 was coincubated with His-PRAK fusion protein. Furthermore, a substantially increased phosphorylation of endogenous DJ-1 in response to $\mathrm{H}_{2} \mathrm{O}_{2}$-induced oxidative stress was observed in $\mathrm{PRAK}^{+/+}$cells but not in $\mathrm{PRAK}^{-/-}$ cells. These data clearly demonstrate a PRAK-dependent phosphorylation of DJ-1.

Next, we attempted to clarify the biological significance of sequestering DJ-1 in the nucleus by PRAK in response to oxidative stress. Recent studies have revealed that DJ-1 functions as a new type of $\mathrm{H}_{2} \mathrm{O}_{2}$ scavenger [51]; however, DJ-1 protects against oxidative stress-induced cell death via its sequestration of Daxx, a death protein in the nucleus, thus preventing subsequent activation of ASK1-mediated cell death pathway, rather than its direct effect of scavenging $\mathrm{H}_{2} \mathrm{O}_{2}$ [30]. Based on these findings, we hypothesized that PRAK facilitates DJ-1 to sequester Daxx in the nucleus, thus protecting against oxidative stress-induced cell death. To test this, we treated cells with $\mathrm{H}_{2} \mathrm{O}_{2}$ and observed that, in $\mathrm{PRAK}^{+/+}$cells, the majority of DJ-1 and Daxx were still colocalized in the nucleus, whereas most DJ-1 and Daxx in $\mathrm{PRAK}^{-/}$cells translocated from the nucleus into the cytoplasm, demonstrating that, without PRAK, DJ-1 fails to sequester Daxx in the nucleus in response to oxidative stress; as a result, more Daxx translocate into the cytoplasm where it triggers ASK1-associated cell death pathway. Consistent with this, we observed a substantially increased cell death in $\mathrm{H}_{2} \mathrm{O}_{2}$ treated $\mathrm{PRAK}^{-/-}$cells compared to $\mathrm{H}_{2} \mathrm{O}_{2}$-treated PRAK ${ }^{+/+}$ cells. In supporting our finding, a recent study by Han and colleagues [52] has reported that PRAK plays a key role in rasinduced senescence and tumor suppression by directly phosphorylating and activating the tumor-suppressor protein $\mathrm{p} 53$, indicating that PRAK possesses a diverse range of biological functions dependent on its downstream interacting partners.

Taken together, we identified DJ-1 as a novel interacting protein for PRAK. PRAK preferentially colocalizes with DJ-1 and leads to DJ-1 activation, which in turn facilitates DJ-1 to sequester Daxx in the nucleus, preventing oxidative stressinduced cell death. Further elucidation of molecular mechanisms underlying the interaction of PRAK, DJ-1, and Daxx may unravel a novel cytoprotective function of PRAK in response to oxidative stress.

\section{Abbreviations \\ $\mathrm{AD}$ : \\ ASK1: \\ DBD: \\ ERK3: \\ FRET: \\ GST: \\ HSP27: \\ Activation domain \\ MAPK: Apoptosis signal-regulating kinase 1 \\ MAPKAPK5: Mitogen-activated protein kinase activated protein kinase 5 \\ NES: $\quad$ Nuclear export sequence \\ Ni-NTA: Nickel-nitrilotriacetic acid \\ NLS: $\quad$ Nuclear localization sequence \\ PRAK: $\quad$ p38 regulated/activated kinase.}

\section{Conflict of Interests}

The authors declare no conflict of interests regarding the publication of this paper.

\section{Authors' Contribution}

J. Tang and J. Liu contributed equally to this work.

\section{Acknowledgments}

This study was supported by the National Key Basic Research (973) Program of China (2010CB529704), the National Natural Science Foundation of China (81030055, 81372030, and 81272149), and Guangdong Provincial Natural Science Foundation (10251051501000003). 


\section{References}

[1] K. Giehl, B. Skripczynski, A. Mansard, A. Menke, and P. Gierschik, "Growth factor-dependent activation of the Ras-RafMEK-MAPK pathway in the human pancreatic carcinoma cell line PANC-1 carrying activated K-ras: implications for cell proliferation and cell migration," Oncogene, vol. 19, no. 25, pp. 2930-2942, 2000.

[2] P. Rosini, G. De Chiara, M. Lucibello, E. Garaci, F. Cozzolino, and M. Torcia, "NGF withdrawal induces apoptosis in CESS B cell line through p38 MAPK activation and Bcl-2 phosphorylation," Biochemical and Biophysical Research Communications, vol. 278, no. 3, pp. 753-759, 2000.

[3] T. Seufferlein, D. J. Withers, and E. Rozengurt, "Reduced requirement of mitogen-activated protein kinase (MAPK) activity for entry into the $S$ phase of the cell cycle in Swiss 3T3 fibroblasts stimulated by bombesin and insulin," The Journal of Biological Chemistry, vol. 271, no. 35, pp. 21471-21477, 1996.

[4] J. S. Zhang, W. G. Feng, C. L. Li, X. Y. Wang, and Z. L. Chang, "NF- $\kappa$ B regulates the LPS-induced expression of interleukin 12 p40 in murine peritoneal macrophages: Roles of PKC, PKA, ERK, p38 MAPK, and proteasome," Cellular Immunology, vol. 204, no. 1, pp. 38-45, 2000.

[5] S. Ludwig, A. Hoffmeyer, M. Goebeler et al., "The stress inducer arsenite activates mitogen-activated protein kinases extracellular signal-regulated kinases 1 and 2 via a MAPK kinase 6/p38- dependent pathway," The Journal of Biological Chemistry, vol. 273, no. 4, pp. 1917-1922, 1998.

[6] R. Janknecht, D. Monté, J.-L. Baert, and Y. de Launoit, "The ETS-related transcription factor ERM is a nuclear target of signaling cascades involving MAPK and PKA," Oncogene, vol. 13, no. 8, pp. $1745-1754,1996$.

[7] Q. Wang and C. M. Doerschuk, "The p38 mitogen-activated protein kinase mediates cytoskeletal remodeling in pulmonary microvascular endothelial cells upon intracellular adhesion molecule-1 ligation," Journal of Immunology, vol. 166, no. 11, pp. 6877-6884, 2001.

[8] R. R. Baliga, D. R. Pimental, Y.-Y. Zhao et al., "NRG-1-induced cardiomyocyte hypertrophy. Role of PI-3-kinase, p70(S6K), and MEK-MAPK-RSK," American Journal of Physiology-Heart and Circulatory Physiology, vol. 277, no. 5, pp. H2026-H2037, 1999.

[9] A. L. Jagolino and W. M. Armstead, "PTK, MAPK, and NOC/oFQ impair hypercapnic cerebrovasodilation after hypoxia/ischemia," The American Journal of Physiology-Heart and Circulatory Physiology, vol. 284, no. 1, pp. H101-H107, 2003.

[10] L. Chen, L. Liu, Y. Luo, and S. Huang, "MAPK and mTOR pathways are involved in cadmium-induced neuronal apoptosis," Journal of Neurochemistry, vol. 105, no. 1, pp. 251-261, 2008.

[11] M. Khatri and J. M. Sharma, "Infectious bursal disease virus infection induces macrophage activation via p38 MAPK and NF- $\kappa$ B pathways," Virus Research, vol. 118, no. 1-2, pp. 70-77, 2006.

[12] M. Matsumoto-Ida, Y. Takimoto, T. Aoyama, M. Akao, T. Takeda, and T. Kita, "Activation of TGF- $\beta 1$-TAK1-p38 MAPK pathway in spared cardiomyocytes is involved in left ventricular remodeling after myocardial infarction in rats," American Journal of Physiology: Heart and Circulatory Physiology, vol. 290, no. 2, pp. H709-H715, 2006.

[13] L. New, Y. Jiang, M. Zhao et al., "PRAK, a novel protein kinase regulated by the p38 MAP kinase," The EMBO Journal, vol. 17, no. 12 , pp. 3372-3384, 1998.
[14] O.-M. Seternes, T. Mikalsen, B. Johansen et al., "Activation of MK5/PRAK by the atypical MAP kinase ERK3 defines a novel signal transduction pathway," EMBO Journal, vol. 24, no. 4, pp. 4780-4791, 2005.

[15] A. de La Mota-Peynado, J. Chernoff, and A. Beeser, "Identification of the atypical MAPK Erk3 as a novel substrate for p21-activated Kinase (Pak) activity," The Journal of Biological Chemistry, vol. 286, no. 15, pp. 13603-13611, 2011.

[16] E. Åberg, K. M. Torgersen, B. Johansen, S. M. Keyse, M. Perander, and O.-M. Seternes, "Docking of PRAK/MK5 to the atypical MAPKs ERK3 and ERK4 defines a novel MAPK interaction motif," The Journal of Biological Chemistry, vol. 284, no. 29, pp. 19392-19401, 2009.

[17] P. Déléris, M. Trost, I. Topisirovic et al., "Activation loop phosphorylation of ERK3/ERK4 by group I p21-activated kinases (PAKs) defines a novel PAK-ERK3/4-MAPK-activated protein kinase 5 signaling pathway," The Journal of Biological Chemistry, vol. 286, no. 8, pp. 6470-6478, 2011.

[18] N. Gerits, T. Mikalsen, S. Kostenko, A. Shiryaev, M. Johannessen, and U. Moens, "Modulation of F-actin rearrangement by the cyclic AMP/cAMP-dependent protein kinase (PKA) pathway is mediated by MAPK-activated protein kinase 5 and requires PKA-induced nuclear export of MK5," Journal of Biological Chemistry, vol. 282, no. 51, pp. 37232-37243, 2007.

[19] S. Kostenko, M. Johannessen, and U. Moens, "PKA-induced Factin rearrangement requires phosphorylation of Hsp27 by the MAPKAP kinase MK5," Cellular Signalling, vol. 21, no. 5, pp. 712-718, 2009.

[20] N. Yoshizuka, M. Lai, R. Liao et al., "PRAK suppresses oncogenic ras-induced hematopoietic cancer development by antagonizing the JNK pathway," Molecular Cancer Research, vol. 10, no. 6, pp. 810-820, 2012.

[21] H. Zheng, A. Seit-Nebi, X. Han et al., "A posttranslational modification cascade involving p38, Tip60, and PRAK mediates oncogene-induced senescence," Molecular Cell, vol. 50, no. 5, pp. 699-710, 2013.

[22] N. Yoshizuka, R. M. Chen, Z. Xu et al., "A novel function of p38regulated/activated kinase in endothelial: cell migration and tumor angiogenesis," Molecular and Cellular Biology, vol. 32, no. 3, pp. 606-618, 2012.

[23] K. T. Chow, G. A. Timblin, S. M. McWhirter, and M. S. Schlissel, "MK5 activates Rag transcription via Foxol in developing B cells," Journal of Experimental Medicine, vol. 210, no. 8, pp. 1621$1634,2013$.

[24] S. Kostenko, G. Dumitriu, K. J. Laegreid, and U. Moens, "Physiological roles of mitogen-activated-protein-kinase-activated p38-regulated/activated protein kinase," World Journal of Biological Chemistry, vol. 2, pp. 73-89, 2011.

[25] M. Zheng, Y.-H. Wang, X.-N. Wu et al., "Inactivation of Rheb by PRAK-mediated phosphorylation is essential for energydepletion-induced suppression of mTORC1," Nature Cell Biology, vol. 13, no. 3, pp. 263-272, 2011.

[26] L. New, Y. Jiang, and J. Han, "Regulation of PRAK subcellular location by $\mathrm{p} 38$ MAP kinases," Molecular Biology of the Cell, vol. 14, no. 6, pp. 2603-2616, 2003.

[27] D. Nagakubo, T. Taira, H. Kitaura et al., "DJ-1, a novel oncogene which transforms mouse NIH3T3 cells in cooperation with ras," Biochemical and Biophysical Research Communications, vol. 231, no. 2, pp. 509-513, 1997.

[28] Z. Xia and Y. Liu, "Reliable and global measurement of fluorescence resonance energy transfer using fluorescence microscopes," Biophysical Journal, vol. 81, no. 4, pp. 2395-2402, 2001. 
[29] H. Y. Chang, H. Nishitoh, X. Yang, H. Ichijo, and D. Baltimore, "Activation of Apoptosis signal-regulating kinase 1 (ASK1) by the adapter protein Daxx," Science, vol. 281, no. 5384, pp. 1860$1863,1998$.

[30] E. Junn, H. Taniguchi, B. S. Jeong, X. Zhao, H. Ichijo, and M. M. Mouradian, "Interaction of DJ-1 with Daxx inhibits apoptosis signal-regulating kinase 1 activity and cell death," Proceedings of the National Academy of Sciences of the United States of America, vol. 102, no. 27, pp. 9691-9696, 2005.

[31] R. H. Kim, M. Peters, Y. Jang et al., "DJ-1, a novel regulator of the tumor suppressor PTEN," Cancer Cell, vol. 7, no. 3, pp. 263-273, 2005.

[32] F. Le Naour, D. E. Misek, M. C. Krause et al., "Proteomics-based identification of RS/DJ-1 as a novel circulating tumor antigen in breast cancer," Clinical Cancer Research, vol. 7, no. 11, pp. 33283335, 2001.

[33] D. Zhang, S. G. Lim, and E. S. C. Koay, "Proteomic identification of down-regulation of oncoprotein DJ-1 and proteasome activator subunit 1 in hepatitis B virus-infected well-differentiated hepatocellular carcinoma," International Journal of Oncology, vol. 31, no. 3, pp. 577-584, 2007.

[34] M. Okada, K.-I. Matsumoto, T. Niki, T. Taira, S. M. M. IguchiAriga, and H. Ariga, "DJ-1, a target protein for an endocrine disrupter, participates in the fertilization in mice," Biological and Pharmaceutical Bulletin, vol. 25, no. 7, pp. 853-856, 2002.

[35] K. Yoshida, Y. Sato, M. Yoshiike, S. Nozawa, H. Ariga, and T. Iwamoto, "Immunocytochemical localization of DJ-1 in human male reproductive tissue," Molecular Reproduction and Development, vol. 66, no. 4, pp. 391-397, 2003.

[36] K. Takahashi, T. Taira, T. Niki, C. Seino, S. M. M. Iguchi-Ariga, and $\mathrm{H}$. Ariga, "DJ-1 positively regulates the androgen receptor by impairing the binding of PIASx alpha to the receptor," The Journal of Biological Chemistry, vol. 276, no. 40, pp. 3755637563, 2001.

[37] T. Niki, K. Takahashi-Niki, T. Taira, S. M. M. Iguchi-Ariga, and H. Ariga, "DJBP: a novel DJ-1-binding protein, negatively regulates the androgen receptor by recruiting histone deacetylase complex, and DJ-1 antagonizes this inhibition by abrogation of this complex," Molecular Cancer Research, vol. 1, no. 4, pp. 247261, 2003.

[38] T. Taira, S. M. M. Iguchi-Ariga, and H. Ariga, "Co-localization with DJ-1 is essential for the androgen receptor to exert its transcription activity that has been impaired by androgen antagonists," Biological and Pharmaceutical Bulletin, vol. 27, no. 4, pp. 574-577, 2004.

[39] T. Pitkänen-Arsiola, J. E. Tillman, G. Gu et al., "Androgen and anti-androgen treatment modulates androgen receptor activity and DJ-1 stability," Prostate, vol. 66, no. 11, pp. 1177-1193, 2006.

[40] J. E. Tillman, J. Yuan, G. Gu et al., "DJ-1 binds androgen receptor directly and mediates its activity in hormonally treated prostate cancer cells," Cancer Research, vol. 67, no. 10, pp. 4630-4637, 2007.

[41] Y. Shinbo, T. Niki, T. Taira et al., "Proper SUMO-1 conjugation is essential to DJ-1 to exert its full activities," Cell Death and Differentiation, vol. 13, no. 1, pp. 96-108, 2006.

[42] S. Shendelman, A. Jonason, C. Martinat, T. Leete, and A. Abeliovich, "DJ-1 is a redox-dependent molecular chaperone that inhibits $\alpha$-synuclein aggregate formation," PLoS Biology, vol. 2, no. 11, article e362, pp. 1764-1773, 2004.

[43] R. H. Kim, P. D. Smith, H. Aleyasin et al., "Hypersensitivity of DJ-1-deficient mice to 1-methyl-4-phenyl-1,2,3,6- tetrahydropyrindine (MPTP) and oxidative stress," Proceedings of the
National Academy of Sciences of the United States of America, vol. 102, no. 14, pp. 5215-5220, 2005.

[44] C. Martinat, S. Shendelman, A. Jonason et al., "Sensitivity to oxidative stress in DJ-1-deficient dopamine neurons: an ESderived cell model of primary Parkinsonism," PLoS Biology, vol. 2, no. 11, pp. 1755-1763, 2004.

[45] J. A. Olzmann, K. Brown, K. D. Wilkinson et al., "Familial Parkinson's disease-associated L166P mutation disrupts DJ-1 protein folding and function," The Journal of Biological Chemistry, vol. 279, no. 9, pp. 8506-8515, 2004.

[46] K. Görner, E. Holtorf, S. Odoy et al., "Differential effects of Parkinson's disease-associated mutations on stability and folding of DJ-1," The Journal of Biological Chemistry, vol. 279, no. 8, pp. 6943-6951, 2004.

[47] D. J. Moore, L. Zhang, J. Troncoso et al., "Association of DJ-1 and parkin mediated by pathogenic DJ-1 mutations and oxidative stress," Human Molecular Genetics, vol. 14, no. 1, pp. 71-84, 2005.

[48] X. Tao and L. Tong, "Crystal structure of human DJ-1, a protein associated with early onset Parkinson's disease," The Journal of Biological Chemistry, vol. 278, no. 33, pp. 31372-31379, 2003.

[49] D. W. Miller, R. Ahmad, S. Hague et al., "L166P mutant DJ-1, causative for recessive Parkinson's disease, is degraded through the ubiquitin-proteasome system," Journal of Biological Chemistry, vol. 278, no. 38, pp. 36588-36595, 2003.

[50] T. Taira, K. Takahashi, R. Kitagawa, S. M. M. Iguchi-Ariga, and H. Ariga, "Molecular cloning of human and mouse DJ-1 genes and identification of Sp1-dependent activation of the human DJ1 promoter," Gene, vol. 263, no. 1-2, pp. 285-292, 2001.

[51] T. Taira, Y. Saito, T. Niki, S. M. M. Iguchi-Ariga, K. Takahashi, and $\mathrm{H}$. Ariga, "DJ-1 has a role in antioxidative stress to prevent cell death," EMBO Reports, vol. 5, no. 2, pp. 213-218, 2004.

[52] P. Sun, N. Yoshizuka, L. New et al., "PRAK Is Essential for rasInduced Senescence and Tumor Suppression," Cell, vol. 128, no. 2, pp. 295-308, 2007. 


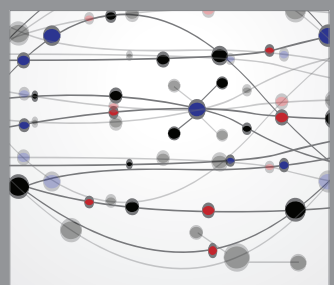

The Scientific World Journal
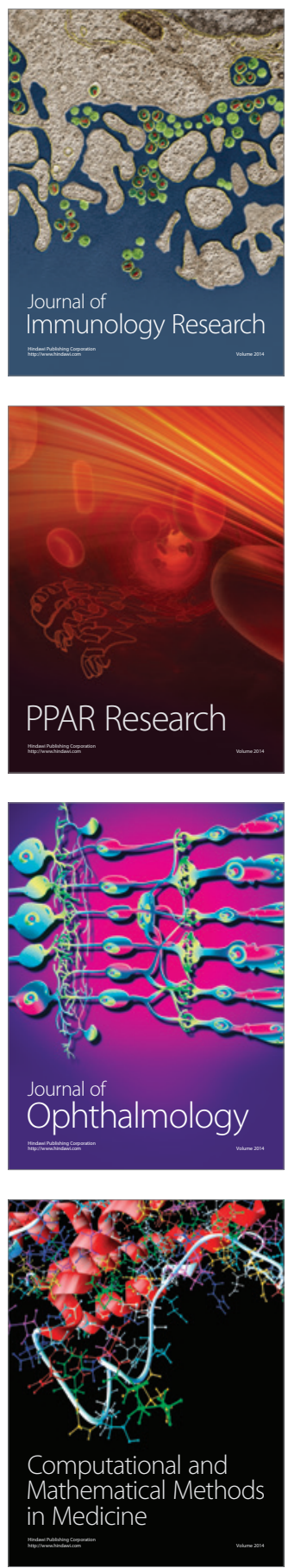

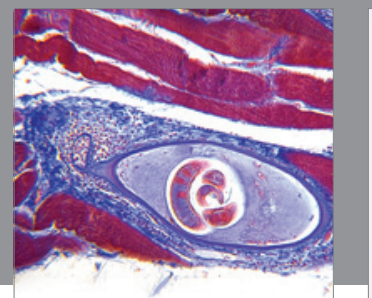

Gastroenterology

Research and Practice
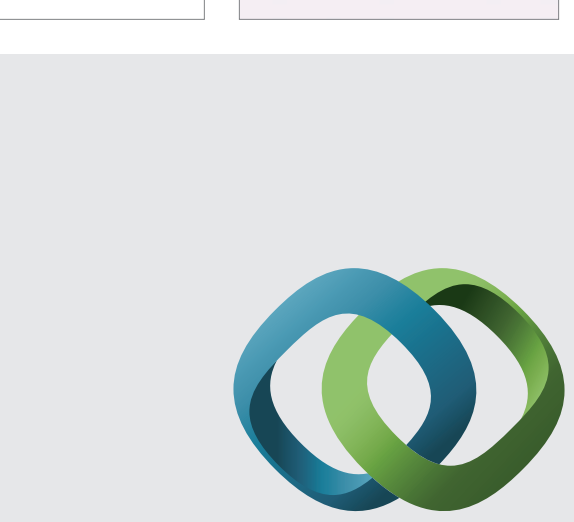

\section{Hindawi}

Submit your manuscripts at

http://www.hindawi.com
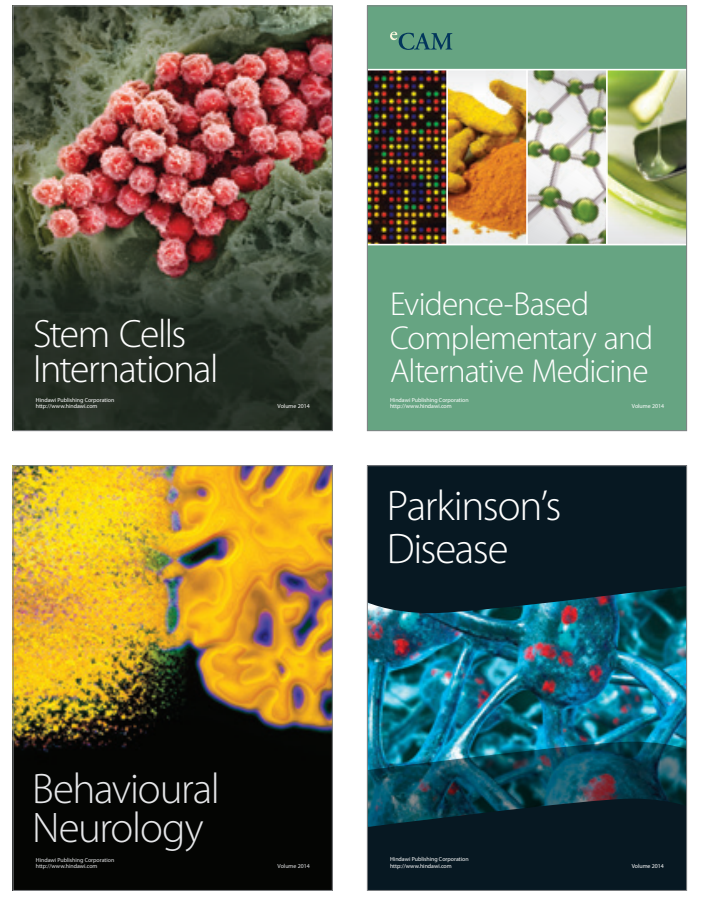
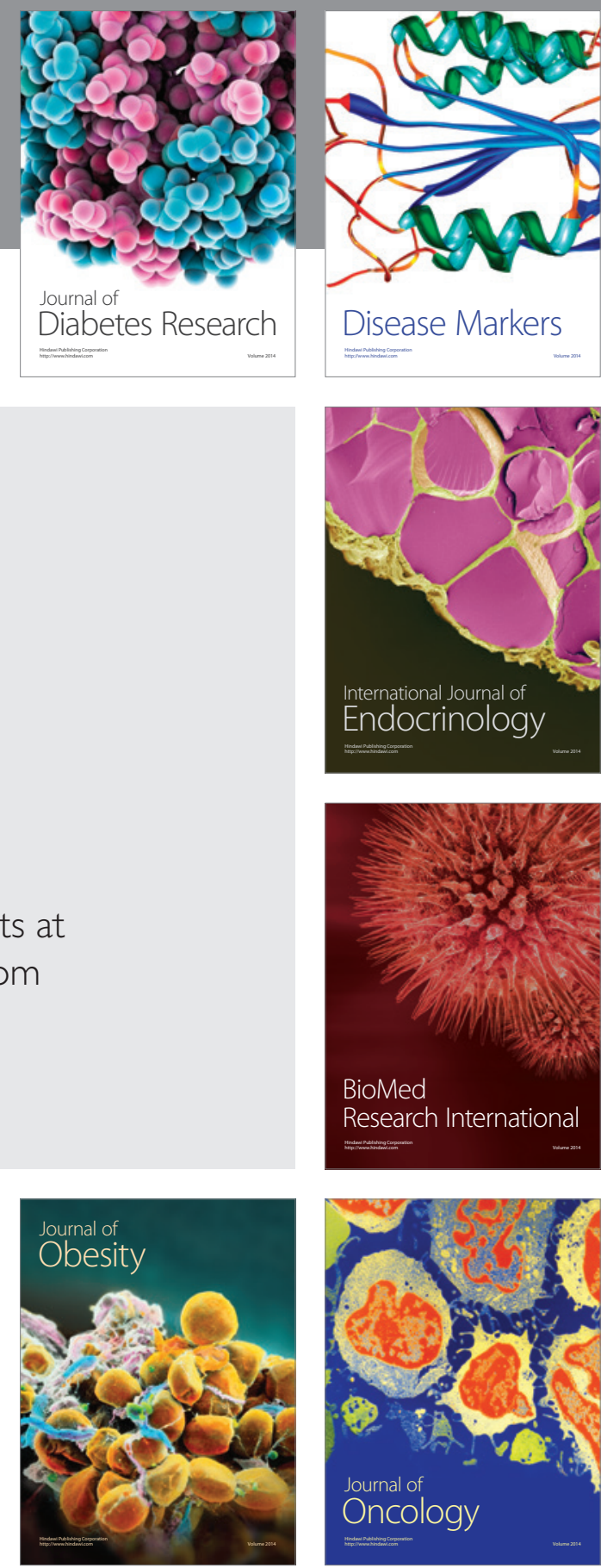

Disease Markers
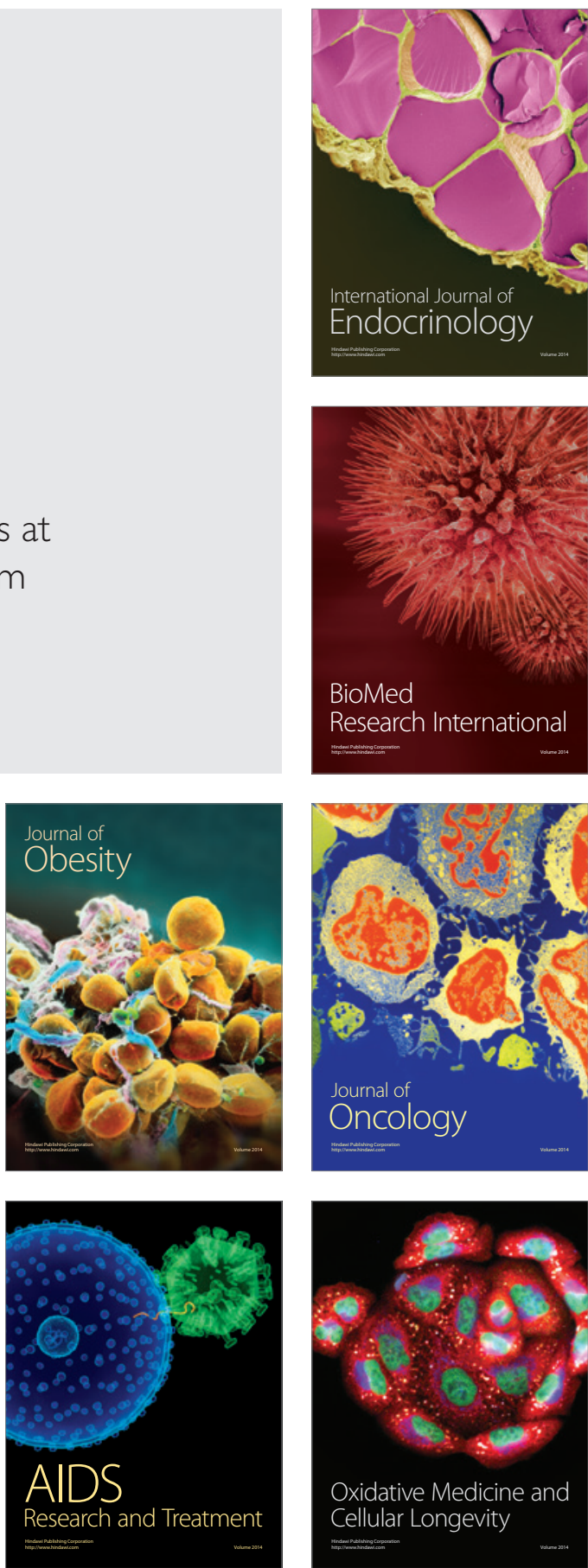